\title{
Antigen-derived peptides directly engage the unfolded-protein sensor IRE1 $\alpha$ to curb cross-presentation by dendritic cells
}

Ofer Guttman ${ }^{1}$, Adrien Le Thomas ${ }^{1}$, Scot Marsters ${ }^{1}$, David A. Lawrence ${ }^{1}$, Lauren Gutgesell $^{1}$, Jonathan M. Harnoss ${ }^{1}$, Simone M. Haag ${ }^{1}$, Aditya Murthy ${ }^{1}$, Geraldine Strasser $^{1}$, Zora Modrusan ${ }^{2}$, Thomas Wu ${ }^{3}$, Ira Mellman ${ }^{1}$ and Avi Ashkenazi ${ }^{1,4}$

Departments of ${ }^{1}$ Cancer Immunology, ${ }^{2}$ Microchemistry, Proteomics and Lipidomics, and ${ }^{3}$ Oncology Bioinformatics, Genentech, Inc. 1 DNA Way, South San Francisco, CA 94080, USA

${ }^{4}$ Corresponding author

\section{ABSTRACT}

Dendritic cells (DCs) promote adaptive immunity by cross-presenting antigen-based epitopes to $\mathrm{CD}^{+} \mathrm{T}$ cells. DCs process internalized protein antigens into peptides that enter the endoplasmic reticulum (ER) and upload onto major histocompatibility type I (MHC-I) protein complexes for cell-surface transport and cross-presentation.

Perplexingly, DCs often exhibit activation of the ER-stress sensor IRE1 $\alpha$ in the absence of classical ER stress-leaving the underlying mechanism unexplained. Here we show that antigen-derived hydrophobic peptides directly engage ER-resident IRE1 $\alpha$ by masquerading as unfolded proteins. Furthermore, IRE1 $\alpha$ activation depletes MHC-I heavy-chain mRNAs through regulated IRE1 $\alpha$-dependent decay (RIDD), thereby curtailing antigen cross-presentation. In tumor-bearing mice, IRE1 $\alpha$ disruption increased MHC-I expression on tumor-infiltrating DCs, and enhanced recruitment and activation of 
bioRxiv preprint doi: https://doi.org/10.1101/2021.09.10.459738; this version posted September 10, 2021. The copyright holder for this preprint (which was not certified by peer review) is the author/funder, who has granted bioRxiv a license to display the preprint in perpetuity. It is made available under aCC-BY 4.0 International license.

$\mathrm{CD}^{+} \mathrm{T}$ cells. Moreover, IRE1 $\alpha$ inhibition synergized with anti-PD-L1 antibody treatment to cause tumor regression. Our findings elucidate the mechanism and consequence of antigen-driven IRE1 $\alpha$ activation in DCs, yielding a promising combination strategy for cancer immunotherapy. 


\section{INTRODUCTION}

Dendritic cells (DCs) comprise a unique myeloid cell subset that plays a crucial role in antigen presentation during the development and elaboration of adaptive immunity (Mellman \& Steinman, 2001; Steinman, 2007). Certain DC lineages mediate the specialized process of antigen cross-presentation, which initiates cytotoxic $\mathrm{CD} 8^{+} \mathrm{T}$ cell responses (Gatti \& Pierre, 2003; Mellman \& Steinman, 2001; Palucka, Banchereau, \& Mellman, 2010). DCs are highly proficient in acquiring antigens from tissue microenvironments, through endocytosis of soluble proteins or phagocytosis of cell fragments and corpses (Z. Chen et al., 2001; Sallusto, Cella, Danieli, \& Lanzavecchia, 1995). During exposure to a pulse of protein antigen, DCs internalize the polypeptide, which reaches the cytoplasm and undergoes proteasomal processing into shorter peptides (Alloatti, Kotsias, Magalhaes, \& Amigorena, 2016). Subsequently, the transporter associated with antigen processing (TAP), which resides in the ER membrane, enables importation of the peptides into the ER lumen. Within the ER, the peptides are uploaded through chaperone-aided events onto MHC-I protein complexes, which are composed of heavy and light polypeptide chains (Jhunjhunwala, Hammer, \& Delamarre, 2021; Thomas \& Tampe, 2017). The peptide-MHC complexes traffic to the DC surface, where the epitopes are cross-presented to engage cognate $T$ cell receptors (TCRs) on juxtaposing T cells. In cancer, both intrinsic and therapeutic mechanisms require efficient $\mathrm{DC}$-mediated cross-presentation of tumor antigens to $\mathrm{CD} 8^{+} \mathrm{T}$ cells to achieve effective anti-tumor immunity (Barber et al., 2006; Barry et al., 2018; D. S. Chen \& Mellman, 2013; Garris et al., 2018; Jansen et al., 2019; Spranger et al., 2016). 
However, few treatment strategies are currently available to directly modulate DC crosspresentation.

The ER mediates 3D folding of newly synthesized proteins that are destined for plasma membrane insertion or extracellular secretion. Elevated demand for protein folding causes ER stress and triggers the unfolded protein response (UPR), which drives ER adaptation to restore homeostasis (Hetz, 2012; Walter \& Ron, 2011; Wang \& Kaufman, 2016). The mammalian UPR comprises three key ER-transmembrane proteins: IRE1a, PERK, and ATF6. IRE1a senses ER stress mainly through its ERlumenal domain, and transmits intracellular signals via a cytoplasmic kinaseendoribonuclease module (Cox, Shamu, \& Walter, 1993; K. P. Lee et al., 2008). IRE1 $\alpha$ detects misfolded proteins through indirect and direct mechanisms: Indirect engagement involves unfolded-protein binding to the ER chaperone BiP/GRP78, which otherwise keeps IRE1 $\alpha$ in check (Amin-Wetzel et al., 2017; Bertolotti, Zhang, Hendershot, Harding, \& Ron, 2000). Direct engagement involves unfolded-protein binding to the lumenal domain of IRE $1 \alpha$, through exposed hydrophobic regions that are otherwise buried within correctly folded proteins (Gardner \& Walter, 2011; Karagoz et al., 2017). IRE1 $\alpha$ activates through molecular events that involve dimerization, kinase trans-autophosphorylation, oligomerization, and consequent endoribonuclease (RNase) engagement (Korennykh et al., 2009; Tirasophon, Welihinda, \& Kaufman, 1998).

The IRE1 $\alpha$ RNase performs two central functions: (1) activation of the transcription factor X-box protein 1 spliced (XBP1s) (Hetz, 2012; Walter \& Ron, 2011; Wang \& Kaufman, 2016); (2) depletion of select mRNAs through the process of RIDD (Hollien et al., 2009; Hollien \& Weissman, 2006). XBP1s induces multiple genes that 
support ER-mediated protein folding, as well as ER-associated degradation (ERAD) of misfolded proteins (Acosta-Alvear et al., 2007; Brodsky, 2012; A. H. Lee, Iwakoshi, \& Glimcher, 2003; Smith, Ploegh, \& Weissman, 2011; Travers et al., 2000). RIDD on the other hand depletes specific ER-targeted mRNAs to abate ER load (Hollien, 2013;

Hollien et al., 2009; Hollien \& Weissman, 2006; Lhomond et al., 2018; Maurel, Chevet, Tavernier, \& Gerlo, 2014). RIDD also regulates additional cellular functions by degrading mRNAs whose products control triglyceride and cholesterol metabolism (So et al., 2012); apoptosis (Chang et al., 2018; Lam, Marsters, Ashkenazi, \& Walter, 2020; M. Lu et al., 2014); autophagy (Bae, Moore, Mella, Hayashi, \& Hollien, 2019); antibody production (Tang et al., 2018); and DNA repair (Dufey et al., 2020; Tang et al., 2018).

To process XBP1 mRNA for splicing, the IRE1 $\alpha$ RNase recognizes two stem-loop structures, located 26 nucleotides apart; each loop contains the consensus sequence endomotif CNGCAGC (Calfon et al., 2002; Shen et al., 2001; Yoshida, Matsui, Yamamoto, Okada, \& Mori, 2001). IRE1 $\alpha$ cleaves between the guanine (G) at position 3 and the cytosine (C) at position 4 (Hooks \& Griffiths-Jones, 2011; Peschek, AcostaAlvear, Mendez, \& Walter, 2015). Subsequently, RtcB ligates the resulting 5' and 3' RNA exons are to produce XBP1s (Jurkin et al., 2014; Kosmaczewski et al., 2014; Lu, Liang, \& Wang, 2014; Peschek et al., 2015). In mammals, RIDD typically requires an XBP1-like endomotif, CNGCAGN, within a predicted stem-loop structure (Hollien, 2013; K. Moore \& Hollien, 2015; K. A. Moore, Plant, Gaddam, Craft, \& Hollien, 2013; Oikawa, Tokuda, Hosoda, \& Iwawaki, 2010). Experimental XBP1s disruption artificially increases IRE1 $\alpha$ autophosphorylation and augments RIDD (X. Chen et al., 2014; M. Lu et al., 2014; Osorio et al., 2014). 
DCs exhibit IRE1 $\alpha$ activation in the absence of canonical ER stress (Iwakoshi, Pypaert, \& Glimcher, 2007; Osorio et al., 2014; Tavernier et al., 2017). Gene knockout (KO) studies of XBP1 have indicated divergent effects on antigen cross-presentation in different types of DCs. In CD8 $\alpha^{+} \mathrm{DCs}, X B P 1 \mathrm{KO}$ led to a hyper-activated RIDD phenotype, which disrupted T cell activation by depleting mRNAs encoding specific components of the cross-presentation machinery, i.e., Lamp-1 and TAP binding protein (TAPBP) (Iwakoshi et al., 2007; Osorio et al., 2014; Tavernier et al., 2017). In contrast, in tumor-associated DCs, XBP1 KO led to changes in lipid metabolism, which improved cross-presentation of tumor antigens and consequent anti-tumor T cell activity (CubillosRuiz et al., 2015). In conventional (c) DC1 subpopulations residing in the lung, XBP1 KO together with partial IRE1 $\alpha$ gene disruption reduced DC viability (Tavernier et al., 2017). Pulsing of bone marrow-derived DCs (BMDCs) with melanoma cell lysates as a source of antigens upregulated XBP1s without affecting RIDD, while IRE1a inhibition attenuated cross-presentation to $\mathrm{CD}^{+} \mathrm{T}$ cells (Medel et al., 2018). While these studies implicate IRE $1 \alpha$ in the biological regulation of DCs, the mechanism underpinning the activation of IRE $1 \alpha$ in these cells in the absence of canonical ER stress remains a mystery.

In the present study, we reveal that antigen-derived peptides can directly engage IRE1 $\alpha$ in antigen-pulsed DCs by mimicking the action of misfolded proteins. We further show that antigen-induced IRE $1 \alpha$ stimulation curtails cross-presentation, through specific RIDD-mediated depletion of MHC-I heavy-chain mRNAs. Blocking this negative feedback in tumor-bearing mice by inhibiting IRE1 $\alpha$ upregulated MHC-I levels on DCs and enhanced tumor recruitment and activation of $\mathrm{CD}^{+} \mathrm{T}$ cells. Moreover, IRE1 $\alpha$ 
bioRxiv preprint doi: https://doi.org/10.1101/2021.09.10.459738; this version posted September 10, 2021. The copyright holder for this preprint (which was not certified by peer review) is the author/funder, who has granted bioRxiv a license to display the preprint in perpetuity. It is made available under aCC-BY 4.0 International license.

inhibition cooperated with anti-PD-L1 immune-checkpoint disruption to cause tumor regression. Our findings elucidate an unexpected mechanism underlying IRE1 $\alpha$ activation in DCs, revealing a promising combinatorial strategy for cancer immunotherapy. 


\section{RESULTS}

\section{Antigen pulsing of BMDCs activates IRE1 1}

To seek insight into the mechanism of IRE1 $\alpha$ activation in DCs, we pulsed mouse BMDCs, matured ex vivo with GM-CSF plus IL-4, with the classical protein antigen ovalbumin. In order to cross-present ovalbumin, DCs must internalize the pulsed protein and process it intracellularly; in contrast, DCs can directly present the ovalbumin-based octapeptide SIINFEKL, based on its ability to displace antigens already bound to MHC-I complexes at the cell surface (Alloatti et al., 2016). Ovalbumin pulsing of BMDCs induced concentration- and time-dependent activation of IRE1 $\alpha$, evident by increased protein levels of XBP1s and phospho-IRE1 $\alpha$ (Figure 1A and 1B). Comparable to the tolllike receptor (TLR) agonist polyinosinic:polycytidylic acid (poly-l:C)—previously shown to activate IRE1 $\alpha$ in leukocytes (Martinon, Chen, Lee, \& Glimcher, 2010)—ovalbumin pulsing induced much weaker IRE1 $\alpha$ activation than did the potent pharmacological ERstressor tunicamycin (Figure 1B). In contrast to ovalbumin, SIINFEKL had little effect on IRE1 $\alpha$ activity (Figure 1B), suggesting a requirement for intracellular events. Unlike IRE1 $\alpha$, other UPR sensors, i.e., PERK (assessed by induction of its downstream targets ATF4 and CHOP) and ATF6 (assessed by its proteolytic processing), which responded to ER-stress induction by the proteasome inhibitor MG132, did not show measurable activation in response to ovalbumin pulsing (Figure S1A), indicating specific IRE1 $\alpha$ engagement in the absence of classical ER stress. To verify bona fide IRE1 $\alpha$ activation during ovalbumin pulsing, we added the highly selective kinase-based small molecule IRE1 $\alpha$ inhibitor, G03089668 (G9668) (Figure S1B-D) (Harnoss et al., 2020; Harnoss et al., 2019; Harrington et al., 2015), which completely blocked IRE1 $\alpha$ phosphorylation and 
XBP1s induction. During a 4-hour pulse of ovalbumin, IRE1 $\alpha$ phosphorylation peaked at 2 hours while XBP1s protein peaked at 4 hours (Figure 1C and S1A). Of note, a 1-hour pulsing with ovalbumin followed by washing and incubation in standard media for another 3 hours generated similar levels of XBP1s (data not shown). Taken together, these results indicate a rapid, yet transient, stimulation of IRE1 $\alpha$ in BMDCs in response to ovalbumin pulsing. BMDC pulsing with lysates derived from CT26, 4T1 and EMT6 tumor cells (see below) also activated IRE1 $\alpha$ (Figure 1D). Moreover, pulsing with a different, highly purified recombinant protein, i.e., clinical-grade soluble CD4, also led to IRE1 $\alpha$ activation (Figure 1E), indicating a specific stimulation mechanism independent of potential contamination with bacterial endotoxin (lipopolysaccharide, LPS).

The micropinocytosis inhibitor amiloride (Koivusalo et al., 2010) blocked antigeninduced IRE $1 \alpha$ stimulation in BMDCs (Figure 1E and S1E), demonstrating a requirement for antigen internalization. Furthermore, CRISPR/Cas9-based disruption of the TAP1 gene prevented IRE1 $\alpha$ stimulation in response to ovalbumin (Figure 1F), indicating a requirement for antigenic peptide importation into the ER. As expected (Martinon et al., 2010), BMDCs lacking the TLR adapter MyD88 failed to activate IRE1 $\alpha$ in response to LPS (Figure S1F); importantly, these cells showed unimpeded IRE1 $\alpha$ stimulation in response to ovalbumin, further validating an LPS-independent IRE1 $\alpha$ activation. We obtained similar evidence for LPS-independent IRE $1 \alpha$ activation upon ovalbumin pulsing of Flt3-ligand (Flt3L)-matured BMDCs from WT or MyD88 KO mice (data not shown). Moreover, unlike BMDCs, mouse embryonic fibroblasts (MEFs) did not display detectable IRE1 $\alpha$ activation after exposure to ovalbumin (Figure S1G), suggesting a BMDC-specific mechanism. Taken together, these results suggest that 
IRE1 $\alpha$ engagement in DCs in response to a pulse of a protein antigen occurs independently of LPS and requires antigen uptake as well as importation of antigenderived peptides into the ER.

\section{Antigen-derived peptides can directly engage IRE1a}

In the context of classical ER stress, otherwise buried hydrophobic segments of unfolded proteins can directly engage the ER-lumenal domain of IRE $1 \alpha$ (Gardner \& Walter, 2011). Although general UPR activation was absent during antigen pulsing of DCs (Figure S1A and S1B), we reasoned that antigen-derived peptides may directly engage IRE $1 \alpha$ by mimicking the action of unfolded proteins. To examine this possibility, we first compared the ability of heat-denatured and native forms of the ovalbumin antigen to bind to a recombinant protein comprising the IRE1 $\alpha$ lumenal domain fused to an Fc tag (LD-Fc). Whereas heat-denatured ovalbumin displayed specific and saturable binding to immobilized IRE1 $\alpha$ LD-Fc, native ovalbumin showed little binding over background (Figure 2A). We estimated a Kd of $\sim 300 \pm 75 \mu \mathrm{M}$ for denatured ovalbumin, in line with affinities previously reported for unfolded-protein binding to IRE1 $\alpha$ LD (Gardner \& Walter, 2011). Co-immunoprecipitation studies confirmed concentrationdependent association of heat-denatured ovalbumin to IRE1 $\alpha$ LD-Fc, whereas native ovalbumin again did not show appreciable binding (Figure 2B). We obtained similar results by acidic $(\mathrm{pH}=2)$ or basic $(\mathrm{pH}=10)$ ovalbumin denaturation (data not shown). Thus, ovalbumin denaturation permits direct binding to IRE1 $\alpha$ 's LD.

Next, to determine whether specific ovalbumin subsegments could interact with IRE1 $\alpha$, we generated a "tiled" peptide array spanning the polypeptide sequence- 
consisting of 18 amino-acid long synthetic peptides with a 3-residue overlap, as previously described (Gardner \& Walter, 2011). We spotted the peptides onto a membrane and examined binding of IRE $1 \alpha$ LD-Fc, using horseradish peroxidase-based colorimetric detection. To test an additional antigen, we generated a similar peptide array based on the GP70 protein, which is expressed by CT26 colorectal cancer cells (Takeda et al., 2000). The analyses revealed that 34/123 ovalbumin peptides (clustered in 10 regions) and 64/210 GP70 peptides (19 regions) displayed significant binding to IRE1 $\alpha$ LD-FC (Figure 2C and S2A). In contrast, arrayed peptides derived from these antigens did not exhibit detectable binding to CD4-Fc under identical conditions (data not shown).

We next evaluated the importance of hydrophobic side-chains for peptide binding. We synthesized biotin-tagged peptides corresponding to two binding and one non-binding segments of the tiled ovalbumin array (B1, B2, and B3), and mutated variants of the binders with hydrophobic residues substituted by aspartic acids (B1', B2') (Figure S2B). We incubated each peptide with FLAG-tagged IRE1 $\alpha$ LD, stabilized formed complexes by chemical crosslinking, and visualized them by anti-biotin immunoblotting. Whereas peptide B3 showed no significant interaction, B1 and B2 exhibited specific binding, associating not only with monomers but also with apparent dimers or oligomers of IRE1 $\alpha$ LD-FLAG (Figure 2D). In contrast to B1 and B2, mutated peptides B1' and B2' failed to show significant binding, indicating a critical role for hydrophobic residues in B1 and B2 for interaction with IRE1 $\alpha$ LD.

To test whether ovalbumin-based peptides can associate with IRE $1 \alpha$ in a cellular setting, we transfected HEK293 cells with cDNA constructs encoding shorter Myc- 
tagged versions of $\mathrm{B} 1, \mathrm{~B} 2$ and $\mathrm{B} 3(\mathrm{M} 1, \mathrm{M} 2$ and $\mathrm{M} 3)$ _fused to a signal sequence for direct ER targeting (Figure S2B). Immunoprecipitation with anti-Myc antibody followed by immunoblotting with anti-IRE1 $\alpha$ revealed specific co-immunoprecipitation of Myctagged peptides with IRE1 $\alpha$ (Figure 2E). Analyzing the signal ratios for IRE1 $\alpha$ over Myc confirmed markedly greater IRE1 $\alpha$ interaction for M1 and M2 as compared to M3. To assess functional IRE $1 \alpha$ engagement, we transfected U20S cells with similar cDNA plasmids encoding a series of three peptides each representing M1, M2, or M3 (Figure S2B). We measured IRE1 $\alpha$ activation by RT-QPCR analysis of mRNA transcripts for XBP1s and XBP1u, as well as the RIDD targets CD59 and DGAT2. The M1 and M2 peptides functionally engaged IRE $1 \alpha$, as evident by upregulation of XBP1s and depletion of the RIDD-targeted mRNAs encoding CD59 and DGAT2 in comparison to non-transfected controls and peptide M3, which showed no activation above vector controls (Figure 2F). Thus, congruent with the results obtained with the corresponding synthetic peptides in a cell-free setting (Figure 2D), ovalbumin-derived, ER-targeted peptides can specifically bind to the ER-resident IRE1 $\alpha$ protein within cells and stimulate its endoribonuclease activity in a manner that corresponds to their direct ability to bind to IRE1 $\alpha$.

\section{IRE1 $\alpha$ inhibition in BMDCs augments cross-presentation}

To examine whether antigen-induced IRE1 $\alpha$ activation impacts cross-presentation, we pulsed BMDCs with ovalbumin in the absence or presence of G9668. We then tested BMDC capacity to activate mouse splenic OT-I CD8 ${ }^{+} \mathrm{T}$ cells, which express a transgenic TCR specific to the SIINFEKL epitope. During SIINFEKL pulsing, IRE1 $\alpha$ 
inhibition with G9668 had little effect; however, upon ovalbumin pulsing, it significantly and reproducibly augmented subsequent induction of OT-I CD8 ${ }^{+}$T-cell proliferation by 20\% (Figure 3A and S3A). To confirm LPS-independent augmentation, we pulsed BMDCs with endotoxin-free ovalbumin (EF-OVA); comparably, IRE $1 \alpha$ inhibition in this setting augmented OT-I CD8 ${ }^{+}$T-cell proliferation by 29\% (Figure 3A). Furthermore, G9668 treatment during pulsing of Flt3L-matured BMDCs with either ovalbumin or EFOVA increased OT-I CD8+ T-cell proliferation by $23 \%$ or $24 \%$, respectively (Figure $3 \mathrm{~B}$ and S3A). Importantly, G9668 did not directly affect proliferation or activation of naïve $\mathrm{CD}^{+}$or $\mathrm{CD}^{+}$splenic T cells upon TCR stimulation with anti-CD3 plus anti-CD28 antibodies (Figure S3B and S3C). Moreover, in contrast to $\mathrm{CD}^{+} \mathrm{T}$ cell stimulation, IRE1 $\alpha$ inhibition during ovalbumin pulsing did not alter MHC class II-restricted activation of splenic OT-Il transgenic CD4 ${ }^{+}$T cells, which also harbor an ovalbumin-specific TCR transgene (Figure S3D). Taken together, these results indicate that protein-antigen pulsing of BMDCs leads to LPS-independent IRE1 $\alpha$ activation, which in turn specifically dampens $\mathrm{MHC}$-I-restricted antigen cross-presentation to $\mathrm{CD}^{+} \mathrm{T}$ cells. Functional inhibition of IRE $1 \alpha$ reverses this curbing mechanism, enhancing antigen crosspresentation.

To investigate the impact of IRE $1 \alpha$ inhibition on cross-presentation of tumor antigens, we subcutaneously inoculated BALB/c mice with CT26 cells and allowed tumors to form. We then isolated splenic $\mathrm{CD}^{+} \mathrm{T}$ cells (likely possessing TCRs that can recognize CT26 antigens) from these mice and co-incubated them with BMDCs prepulsed with CT26 cell lysates. Addition of G9668 augmented cross-presentation of CT26 epitopes to cognate splenic CD8 ${ }^{+} \mathrm{T}$ cells by $\sim 25 \%$ (Figure $3 \mathrm{C}$ ), in keeping with 
ovalbumin cross-presentation. Thus, IRE1 $\alpha$ inhibition in BMDCs enhances crosspresentation of tumor-derived antigens.

Next, we turned to interrogate which specific aspect of the cross-presentation process is modulated by IRE $1 \alpha$. IRE1 $\alpha$ inhibition did not alter the uptake of fluorescently-labeled ovalbumin by BMDCs (Figure S3E). On the other hand, IRE1 $\alpha$ inhibition during exposure of BMDCs to ovalbumin or cell lysates significantly increased MHC-I protein expression at the cell surface (Figure 3D), suggesting negative regulation of antigen-driven MHC-I dynamics by IRE1 $\alpha$.

\section{IRE1 $\alpha$ activation depletes MHC-I heavy-chain mRNAs via RIDD}

Earlier work shows that in lymph node-resident CD8 ${ }^{+}$DCs RIDD constitutively suppresses mRNA transcripts encoding certain components of the cross-presentation machinery, such as TAPBP (Osorio et al., 2014). In ovalbumin-pulsed BMDCs, IRE1 $\alpha$ inhibition minimally impacted mRNA levels of TAPBP, nor did it affect transcript abundance of the MHC-I light-chain $\beta-2$ microglobulin ( $\beta-2 M)$, TAP1, or ER aminopeptidase ERAP1; however, it markedly upregulated MHC-I H-2K heavy-chain mRNA levels by 2.8 -fold (Figure S4A).

We therefore considered the possibility that IRE1 $\alpha$ activation in response to antigen pulsing attenuates cross-presentation by decreasing MHC-I heavy-chain mRNAs through RIDD. Supporting this hypothesis, computational examination of mRNA sequences encoding the murine $\mathrm{H}-2 \mathrm{~K}, \mathrm{H}-2 \mathrm{D}$, and $\mathrm{H}-2 \mathrm{~L}$ heavy-chains revealed the presence of consensus IRE $1 \alpha$-targeted stem-loop endomotifs (Figure 4A), whereas $\beta$ - 
2M mRNA did not contain such sequences. To examine whether IRE1 $\alpha$ can directly cleave heavy-chain mRNAs, we incubated a phosphorylated recombinant protein comprising the cytoplasmic kinase-endoribonuclease module of IRE $1 \alpha$ with RNA transcripts encoding $\mathrm{H}-2 \mathrm{~K}, \mathrm{H}-2 \mathrm{D}$, and $\mathrm{H}-2 \mathrm{~L}$. IRE1 $\alpha$ efficiently cleaved all three RNAs (Figure 4B), supporting the involvement of their RIDD-mediated degradation in curbing cross-presentation.

To examine RIDD-mediated depletion in BMDCs, we prevented de novo transcription with actinomycin D. In control-pulsed BMDCs, the mRNA levels of H-2K as well as the canonical RIDD targets CD59 and DGAT2 remained stable over a 24-hour period; in contrast, in antigen-pulsed BMDCs, the levels of both $\mathrm{H}-2 \mathrm{~K}$ and CD59 mRNAs substantially declined over time (Figure 4C). Furthermore, both the kinasebased IRE1 $\alpha$ inhibitor G9668 and the RNase-directed IRE1 $\alpha$ inhibitor $4 \mu 8 \mathrm{c}$ (Cross et al., 2012) substantially rescued mRNAs encoding H-2K, CD59, and DGAT2 (Figure 4D), as well as several other known RIDD targets, i.e., BLOS1, RNF213 and IRF7 (Figure S4B), demonstrating RIDD-based depletion.

Thus, antigen pulsing of DCs activates IRE1 $\alpha$, which curbs cross-presentation by depleting MHC-I heavy-chain mRNAs through RIDD.

\section{IRE1 $\alpha$ inhibition in tumor-bearing mice upregulates MHC-I on tumor DCs and augments $\mathrm{CD}^{+} \mathrm{T}$ cell engagement}

To determine whether the dampening effect of IRE1 $\alpha$ on antigen cross-presentation has functional consequences in vivo, we examined the impact of IRE $1 \alpha$ disruption on 
syngeneic tumor growth in mice. Tumor-cell-autonomous knockout of IRE1 $\alpha$ by

CRISPR/Cas9 had little effect on subcutaneous growth of CT26 colon tumors (Figure S5A and S5B). In contrast, systemic pharmacological inhibition of IRE1 $\alpha$ with G9668 substantially attenuated tumor progression as compared to vehicle treatment (Figure 5A, S5C, and S5D), suggesting enhancement of host-mediated anti-tumor activity. To specifically elucidate potential immune effects, we analyzed by flow cytometry the tumor-associated leukocyte populations after 7 days of treatment. As compared to controls, tumors from G9668-treated mice showed significantly greater infiltration by CD11 ${ }^{+}$MHC class II ${ }^{\text {high }}$ DCs (Figure 5B), specifically belonging to the CDC1 (XCR1 ${ }^{+}$ $\mathrm{CD} 103^{+}$) subpopulation (Figure 5C). Furthermore, tumor-infiltrating cDC1s showed significantly higher surface levels of MHC-I, as well as the RIDD marker CD59, in G9668-treated mice as compared to controls (Figure 5D). Moreover, G9668 treatment led to significantly greater numbers of tumor-infiltrating cytotoxic CD8 ${ }^{+} \mathrm{T}$ cells (Figure $5 \mathrm{E})$, and to higher expression by these cells of the activation markers granzyme B, PD1, and CD44 (Figure 5F). Importantly, staining with recombinant MHC-I tetramer complexes presenting the CT26 tumor antigen GP70 revealed significantly higher levels of tumor-infiltrating GP70-specific $\mathrm{CD}^{+} \mathrm{T}$ cells in G9668-treated mice (Figure 5G). Thus, IRE1 $\alpha$ inhibition attenuates CT26 tumor growth in conjunction with elevated tumor infiltration, MHC-I expression, and tumor-antigen cross-presentation by cDC1s, augmenting the recruitment and activation of tumor-reactive $\mathrm{CD}^{+} \mathrm{T}$ cells.

\section{Single-cell RNAeq demonstrates IRE1 $\alpha$ regulation of MHC-I mRNAs in tumor DCs}


To examine immune modulation in a different tumor model, we used syngeneic 4T1 triple-negative breast cancer (TNBC) cells. In contrast to the CT26 model (Figure S5A and S5B), cell-autonomous knockout of IRE $1 \alpha$ in $4 \mathrm{~T} 1$ cells caused notable tumorgrowth inhibition (TGI) of 53\% (Figure S6A and S6B). Nevertheless, systemic treatment of mice bearing parental IRE $1 \alpha$ wildtype 4T1 tumors with G9668 led to a stronger TGI of 82\% (Figure 6A, S6C and S6D), suggesting both cell-autonomous and host-mediated anti-tumor effects. The myeloid compartment in tumors has been systematically studied by single-cell RNA sequencing (scRNAseq) (Cheng et al., 2021; Mariathasan et al., 2018). We performed scRNAseq after 6 days of treatment to analyze the tumor leukocytic populations. Tumors in G9668-treated mice showed enrichment in both DCs and $\mathrm{CD}^{+} \mathrm{T}$ effector cells, but not in naïve T cells (Figure 6B and 6C). Importantly, tumor-infiltrating DCs in G9668-treated mice displayed significantly higher mRNA levels of $\mathrm{H}-2 \mathrm{~K}$ and $\mathrm{H}-2 \mathrm{D}$ heavy-chains; though not of TAPBP transcripts (Figure 6D). CD59 and DGAT2 mRNAs were insufficiently abundant to enable accurate quantification, but five other RIDD targets that were detected, i.e. BLOS1, FERMT3, IRF7, RNF213 and SPON1, showed significant increases (Figure S6E), confirming RIDD inhibition. Tumors in G9668-treated mice had unaltered levels of M1 macrophages, but showed significantly fewer M2 macrophages and monocytes as compared to controls (Figure S6F). Flow cytometric analysis after 6 days of treatment showed that IRE1 $\alpha$ inhibition significantly increased tumor infiltration by cytotoxic $\mathrm{CD}^{+} \mathrm{T}$ cells and their expression of the activation markers IFN- $\gamma, \mathrm{PD}-1$, and CD69, independent of IRE1 $\alpha$ status in the malignant cells (Figure 6E). These results further support the conclusion that IRE1 $\alpha$ inhibition augments anti-tumor immune responsiveness by increasing MHC-I expression 
on tumor-associated DCs and consequent engagement of tumor-infiltrating cytotoxic $\mathrm{CD}^{+} \mathrm{T}$ cells.

\section{Systemic IRE1a inhibition cooperates with immune checkpoint blockade}

Although immune-checkpoint disruption has transformed patient benefit in a number of cancer settings (Marinelli et al., 2020), further advances are needed to achieve wider effectiveness. To investigate whether IRE1 $\alpha$ inhibition would complement immunecheckpoint blockade, we turned to the orthotopic EMT6 TNBC model, previously found to exhibit partial responsiveness to anti-programmed death ligand (PD-L)1 antibody therapy upon implantation in the mouse mammary fat pad (Mariathasan et al., 2018). Similar to the CT26 model, cell-autonomous IRE1 $\alpha \mathrm{KO}$ in EMT6 cells had minimal impact on tumor growth (Figure S7A and S7B), identifying an additional suitable model to specifically interrogate the impact of IRE $1 \alpha$ inhibition on immune modulation. Treatment of EMT6 tumor bearing mice with either the anti-mouse PD-L1 monoclonal antibody 6E11 or with G9668 partially impaired EMT6 tumor progression (Figure 7A and S7C). Remarkably, combined administration of 6E11 and G9668 led to frank tumor regression with a mean TGI rate of $114 \%$, resulting in significantly better efficacy than either monotherapy $(p<0.01)$. In keeping with the other models, treatment of EMT6 tumor-bearing mice with G9668 for 7 days significantly increased surface levels of MHC-I and CD59 in tumor-infiltrating cDC1s (Figure 7B). Moreover, G9668 increased tumor invasion by cytotoxic $\mathrm{CD}^{+} \mathrm{T}$ cells and their expression of the activation markers IFN- $\gamma$ and granzyme B (Figure 7C). Thus, IRE1 $\alpha$ inhibition effectively complements PD- 
bioRxiv preprint doi: https://doi.org/10.1101/2021.09.10.459738; this version posted September 10, 2021. The copyright holder for this preprint (which was not certified by peer review) is the author/funder, who has granted bioRxiv a license to display the preprint in perpetuity. It is made available under aCC-BY 4.0 International license.

\section{L1-based immune-checkpoint disruption to reverse syngeneic orthotopic tumor}

progression. 


\section{DISCUSSION}

The mechanism of IRE1 $\alpha$ activation in the absence of classical ER stress in DCs has been mysterious (Iwakoshi et al., 2007; Medel et al., 2018; Osorio et al., 2014; Tavernier et al., 2017). Our present findings reveal that exposure of DCs to pulsed protein antigens drives IRE1 $\alpha$ activation through an LPS-independent process analogous to the direct engagement of IRE $1 \alpha$ by unfolded proteins under canonical ER stress. We further show that antigen-induced IRE1 $\alpha$ activity curbs cross-presentation through RIDD-mediated depletion of MHC-I heavy-chain mRNAs. This functional consequence likely represents a negative feedback loop that fine-tunes crosspresentation, perhaps to prevent inappropriate or excessive T-cell activation during sterile tissue injury. Importantly, the disruption of this inherent negative feedback by inhibiting IRE1 $\alpha$ cooperates with immune-checkpoint blockade to enhance anti-tumor immune responses, revealing exciting potential for therapeutic translation.

Our BMDC studies showed that antigen pulsing selectively activates IRE1 $\alpha$ but not PERK or ATF6, excluding the standard UPR as a key mechanistic driver. This contrasts with plasmacytoid DCs (pDCs), which do not mediate cross-presentation, and interestingly display constitutive activation of PERK (Mendes et al., 2021). BMDC pulsing with different protein antigens, or with lysates of several cancer cell lines, induced significant levels of IRE $1 \alpha$ activity. Although these levels were markedly weaker than those induced by strong pharmacological ER stressors, antigenic IRE1 $\alpha$ stimulation was highly reproducible, reaching peak intensity within $2-4$ hours of exposure, and then declining. These rapid yet transient kinetics are consistent with the time frame of antigen uptake, processing, and ER entry. Indeed, our further mechanistic 
dissection indicated that antigen-driven IRE $1 \alpha$ activation requires both pinocytosis and ER importation events, but not TLR signaling.

IRE1 $\alpha$ resides in the ER membrane and responds through its lumenal domain to ER accumulation of unfolded or misfolded proteins during canonical ER stress (Hetz, 2012; Walter \& Ron, 2011). Based on our observation that antigen-induced IRE1 $\alpha$ activation required TAP1 - a critical mediator for importation of antigen-derived peptides into the ER-we reasoned that antigen-based peptides entering the ER may directly engage IRE $1 \alpha$ by masquerading as unfolded or misfolded proteins. Several lines of evidence supported this idea. First, whereas native ovalbumin failed to interact with the IRE1 $\alpha$ LD, unfolded ovalbumin — generated by denaturation with heat or extreme $\mathrm{pH}-$ was capable of direct LD binding, with affinity comparable to that of unfolded proteins (Gardner \& Walter, 2011). Second, specific ovalbumin-based peptides bound to the IRE1 $\alpha$ LD in a manner that required their hydrophobic amino acids. Third, cellular expression of ER-directed ovalbumin-based peptides demonstrated congruent interaction with, and functional engagement of, cellular IRE1 $\alpha$. The lack of stimulation of the other UPR branches in response to antigen pulsing further indicates a direct IRE $1 \alpha$ activation mechanism independent of $\mathrm{BiP}$. Hence, although a nascent protein that is incorrectly folded by the ER and a peptide that lacks 3D structure due to proteolytic cleavage of its parent protein in the cytoplasm are distinct, both can be sensed by IRE1 $\alpha$. Although any protein-producing cell may harbor some constitutive level of IRE1 $\alpha$-peptide interactions, our data suggest that DCs are uniquely capable of IRE1 $\alpha$ activation upon transient exposure to a high concentration of an extracellular protein. Moreover, for DCs, which are highly specialized in antigen cross-presentation, such 
IRE1 $\alpha$ activation can have unique functional consequences. The recent discovery of pervasive functional peptide translation in cells (J. Chen et al., 2020) raises an intriguing question of whether additional peptide modalities besides antigen processing may similarly engage IRE1 $\alpha$.

Earlier work interrogating the involvement of IRE1 $\alpha$ in DC regulation relied primarily on $X B P 1 \mathrm{KO}$ - a strategy that does not completely disrupt, and in some cases even augments, the kinase-endoribonuclease activity of IRE $1 \alpha$. In CD8 ${ }^{+} \mathrm{DCs}, \mathrm{XBP} 1 \mathrm{KO}$ causes artificial RIDD hyper-activation, which leads to mRNA depletion of certain components of the cross-presentation machinery, i.e., LAMP-1, TAPBP, and $\beta 2 \mathrm{M}$ (Osorio et al., 2014). In contrast, BMDC pulsing with melanoma cell lysates activated XBP1 splicing but not RIDD, and XBP1s appeared to promote, rather than disrupt, efficient melanoma antigen cross-presentation (Medel et al., 2018). Direct infection of BMDCs by Toxoplasma gondii led to IRE1 $\alpha$ activation via MyD88-dependent TLR signaling, with decreased cross-presentation upon $X B P 1 \mathrm{KO}$ and partial disruption of IRE1 $\alpha$ (Poncet et al., 2021). The partial disruption of IRE1 $\alpha$ signaling by XBP1 KO left the biological consequence of IRE $1 \alpha$ engagement during antigen cross-presentation incompletely understood.

To impede IRE1 $\alpha$ 's enzymatic activity more fully, we used the highly selective and potent kinase-based IRE1 $\alpha$ inhibitor G9668, which blocks both the kinase and the kinase-controlled endoribonuclease activities of IRE1 $\alpha$. Indeed, G9668 fully disrupted antigen-induced IRE $1 \alpha$ activation in DCs, preventing IRE1 $\alpha$ auto-phosphorylation, as well as consequent RNase-dependent XBP1 splicing and RIDD. While G9668 did not alter DC-surface presentation of ovalbumin-derived SIINFEKL peptide to OT-I CD8 ${ }^{+} \mathrm{T}$ 
cells, it augmented cross-presentation of pulsed full-length ovalbumin, confirming the requirement of intracellular events for IRE1 $\alpha$ activation. Of note, G9668 did not alter MHC-II-restricted antigen presentation to OT-II CD4 ${ }^{+}$T cells, nor did it affect costimulation of naïve $\mathrm{CD}^{+}$or $\mathrm{CD}^{+} \mathrm{T}$ cells. Enhancement by $\mathrm{G} 9668$ was not limited to the OT-I model, as it also applied to cross-presentation of CT26-derived antigens to splenic $\mathrm{CD}^{+} \mathrm{T}$ cells from CT26 tumor-bearing mice. Thus, the engagement of IRE1 $\alpha$ during antigen processing within DCs selectively curtails MHC-I-restricted crosspresentation, providing negative feedback to modulate T cell activation.

Our investigation of how IRE $1 \alpha$ curtails cross-presentation underscores RIDD as an important mechanism that depletes mRNAs encoding MHC-I heavy chains. This agrees in principle with the earlier observation of RIDD-mediated depletion of other cross-presentation components (Osorio et al., 2014; Tavernier et al., 2017), although the specific RIDD targets differ. Perhaps distinct mRNAs are depleted upon more subtle RIDD activation by antigen, as compared to RIDD hyper-activation by XBP1 KO. Our analysis revealed the presence of consensus stem-loop endomotifs within each of the three mouse MHC-I heavy-chain mRNAs, i.e., $\mathrm{H}-2 \mathrm{~K}, \mathrm{H}-2 \mathrm{D}$ and $\mathrm{H}-2 \mathrm{~L}$. We verified the cleavage of all three transcripts by the phosphorylated kinase-endoribonuclease module IRE1 $\alpha$ in vitro, as well as of $\mathrm{H}-2 \mathrm{~K}$ mRNA in antigen-pulsed BMDCs. Moreover, our scRNAseq analysis demonstrated that G9668 treatment elevated $\mathrm{H}-2 \mathrm{~K}$ and $\mathrm{H}-2 \mathrm{D}$ transcript levels in tumor-associated DCs, providing further validation of this mechanism in the tumor microenvironment. Of note, multiple human HLA-I A, B and C heavy-chains also contain consensus stem-loop RIDD endomotifs (not shown). Nevertheless, we have recently observed that human IRE1 $\alpha$ can also perform more promiscuous RNase 
activity, termed RIDDLE for RIDD lacking endomotif (Le Thomas et al., submitted), which might account for divergence of IRE1 $\alpha$ RNase targets in different settings.

In three syngeneic tumor models, systemic treatment with G9668 attenuated tumor growth more strongly than did selective IRE1 $\alpha$ disruption in the malignant cells, indicating that IRE1 $\alpha$ activity in the tumor microenvironment supports tumor growth. Flow cytometry and scRNAseq analyses demonstrated that systemic IRE1 $\alpha$ inhibition increased MHC-I heavy chain transcript and surface-protein levels in tumor-infiltrating DCs, mirroring the in vitro BMDC experiments. These changes occurred in conjunction with enhanced tumor infiltration and activation of $\mathrm{CD}^{+} \mathrm{T}$ cells. Functional linkage between the enhancement of the highly specialized cDC1-mediated cross-presentation and $\mathrm{CD}^{+} \mathrm{T}$ cell engagement was strengthened by elevated $\mathrm{MHC}-\mathrm{I}$ tetramer staining. Importantly, combined treatment with anti-PD-L1 antibody and G9668 in the orthotopic EMT6 TNBC model, which is only partially responsive to anti-PD-L1, led to clear tumor regression, establishing non-redundant complementarity of these two modalities.

In conclusion, our studies reveal that pulsed-antigen-derived peptides can directly engage IRE1 $\alpha$ in cross-presenting DCs, explaining the activation of this ERstress sensor in the absence of classical ER stress. Furthermore, by fully blocking IRE1 1 's enzymatic function, we have discovered that IRE1 $\alpha$ controls a negative feedback loop, by depleting MHC-I heavy-chain mRNAs via RIDD, to dampen crosspresentation and curtail consequent $\mathrm{CD}^{+} \mathrm{T}$ cell activation. Excitingly, disruption of this feedback by small-molecule IRE1 $\alpha$ inhibition holds promise for cancer immunotherapy, particularly in combination with anti-PD-L1 inhibition. These findings bring important conceptual advances to seminal previous work identifying a role for XBP1s in 
bioRxiv preprint doi: https://doi.org/10.1101/2021.09.10.459738; this version posted September 10, 2021. The copyright holder for this preprint (which was not certified by peer review) is the author/funder, who has granted bioRxiv a license to display the preprint in perpetuity. It is made available under aCC-BY 4.0 International license.

dysregulated lipid metabolism and in function of tumor-associated DCs (Cubillos-Ruiz et al., 2015), and to studies on IRE1 $\alpha$ disruption in immunodeficient mice (Harnoss et al., 2020; Harnoss et al., 2019; Harrington et al., 2015). 


\section{MATERIALS \& METHODS}

\section{Cell Cultures, BMDC differentiation and Experimental Reagents}

CT26, 4T1, HEK293 and EMT6 cells were originally acquired from ATCC, authenticated by analysis of short tandem repeats and tested to ensure no presence of mycoplasma within 3 mo of use. U20S cells were kindly provided by the Walter Lab of the University of California, San Francisco (UCSF). Cells were grown in RPMI1640 media supplemented with $10 \%$ fetal bovine serum (FBS) (Sigma, St. Louis, MO), 2 mM glutaMAX (Gibco, Amarillo, TX), $100 \mathrm{U} / \mathrm{ml}$ penicillin (Gibco) and $100 \mu \mathrm{g} / \mathrm{ml}$ streptomycin (Gibco). MEFs were obtained as previously described (Holst et al., 2007).

For purification and differentiation of BMDCs, the femur and tibia bones of C57BL/6 mice were flushed with sterile PBS and bone marrow cells were then cultured in RPMI1640 media as described above and further supplemented with $50 \mathrm{mM} \beta 2$ mercaptoethanol (Sigma), $20 \mathrm{ng} / \mathrm{ml}$ granulocyte-macrophage colony-stimulating factor (GM-CSF) (Biolegend, San Diego, CA) and $10 \mathrm{ng} / \mathrm{ml}$ IL-4 (Biolegend) for 9 days, with media being replenished every 3 days of culturing, as described previously (Fernandez et al., 1999). Where indicated, FIt3L-BMDCs were similarly generated using media supplemented with $200 \mathrm{ng} / \mathrm{ml}$ recombinant mouse Flt3L (Peprotech, Cranbury, NJ) (Brasel, De Smedt, Smith, \& Maliszewski, 2000). After 9 days of culture, BMDCs were routinely verified to be $>90 \% \mathrm{CD} 11 \mathrm{C}^{+} \mathrm{MHC}$-II ${ }^{\text {high }}$ by flow cytometry analysis.

Thapsigargin (Sigma) was used at $100 \mathrm{nM}$, tunicamycin (Sigma) was used at 5 $\mu \mathrm{g} / \mathrm{ml}, \mathrm{MG} 132$ (Sigma) was used at $5 \mu \mathrm{M}$, Amiloride (Sigma) was used at $10 \mu \mathrm{M}$, actinomycin D (Sigma) was used at $4 \mu \mathrm{g} / \mathrm{ml}$, LPS (Sigma) was used at $10 \mu \mathrm{g} / \mathrm{ml}$ and poly-l:C (Sigma) was used at $25 \mu \mathrm{g} / \mathrm{ml}$. Ovalbumin (Sigma), endotoxin-free ovalbumin 
(EF-OVA) (EndoFit, InvivoGen, San Diego, CA), SIINFEKL peptide (Sigma), and human CD4-Fc fusion protein (generated in-house at Genentech) were dissolved in PBS prior to pulsing and used at indicated concentrations.

The RNase-based IRE1 $\alpha$ inhibitor $4 \mu 8 \mathrm{C}$ (Cross et al., 2012) was used at $5 \mu \mathrm{M}$. The kinase-based IRE1 $\alpha$ inhibitor G9668 (Harnoss et al., 2020; Harnoss et al., 2019; Harrington et al., 2015) was used as indicated.

For antigen uptake experiments, ovalbumin and CD4-Fc fusion proteins were labelled with allophycocyanin (APC) with the Lightning-Link Labelling Kit (Abcam, Cambridge, UK).

For pulsing with tumor cell lysates, indicated cell lines were grown to confluence, suspended in sterile PBS and subjected to five freeze-thaw cycles with liquid nitrogen and heating at $37^{\circ} \mathrm{C}$. Cell lysates were then normalized by BCA protein concentration measurement (Thermo-Fisher, Waltham, MA).

\section{In Vitro characterization of small-molecule IRE1 $\alpha$ inhibitor G03089668}

Potency of G9668 was analyzed in two assays of IRE1 $\alpha$ activity, with dilutions covering a range of concentrations from $0.2 \mathrm{nM}$ to $10 \mu \mathrm{M}$ in order to determine $\mathrm{IC}_{50}$ values. Inhibition of RNase activity was assessed by the incubation of G9668 with IRE1 $\alpha$ (Q470-L977) and 5'FAM-CAUGUCCGCAGCGCAUG-3'BHQ substrate. Substrate cleavage was monitored kinetically as an increase in fluorescence. Cellular activity was evaluated with the XBP1s-luciferase reporter assay in HEK293 cells stably transfected with the XBP1s-luciferse reporter construct. Briefly, cells were preincubated with G9668 
for 2 hours and subsequently stimulated with Tg (100 nM) for 6 hours. IRE1 $\alpha$-mediated cleavage of the reporter led to luciferase expression which was detected with the addition of luciferin substrate. Kinase selectivity of G9668 against a panel of 220 kinases was measured at a concentration of $1 \mu \mathrm{M}$ with KinomeScan ${ }^{\mathrm{TM}}$ (DiscoverX, Fremont, CA). Fold selectivity was determined by $\mathrm{IC}_{50}$ measurement of competition by G9668 for binding of ATP to each specific kinase that showed significant inhibition by G9668 via KinomeScan ${ }^{\mathrm{TM}}$.

\section{Generation of IRE1 1 KO syngeneic tumor cell lines}

Individual IRE1 $\alpha$-specific sgRNAs were designed using a standard guide scaffold and CRISPR3. The gRNAs were cloned into pLKO_AIO_CMV_Cas9_mCherry, enabling coexpression of each sgRNA, Cas9, and an mCherry-based selection marker following transient transfection into target cells.

sgRNA target sequences used in this study:

IRE1 $\alpha$ gRNA1: TGTTTGTCTCGACCCTGGA

IRE1 $\alpha$ gRNA2: GAGGACGGGCTCCATCAAG

IRE1 $\alpha$ gRNA3: GGAGGCCTGAACCAATTCT

IRE1 $\alpha$ gRNA4: ATGTTATCGACCTCCTGAC

Transfection was with Lipofectamine 3000 (Thermo-Fisher) according to manufacturer's protocol. At 24 hours after transfection, cells were washed once in PBS and resuspended in PBS media containing 3\% BSA Fraction V. The cell suspension was then filtered through a $35 \mathrm{~mm}$ membrane followed by immediate FACS sorting using the 
mCherry selection marker. Single cell clones $(n=96)$ were plated and grown. Clones producing colonies were tested for proper IRE1a disruption by immunoblot.

\section{Immunoblot analysis}

Cells were lysed in PBS solution supplemented with 1X RIPA buffer (Millipore, Burlington, MA) and 2X Halt ${ }^{\mathrm{TM}}$ protease-phosphatase inhibitor cocktail (Thermo-Fisher). Upon clearance, samples were analyzed by SDS-PAGE, electrotransferred to nitrocellulose membranes (Invitrogen) and blocked by $5 \%$ powdered milk in PBSt (PBS supplemented with $0.1 \%$ tween) solution. Development was conducted with ECL reagent (Thermo-Fisher) and ChemiDoc ZRS+ imager (Biorad, Hercules, CA). Antibodies used for western blot analysis include IRE1 $\alpha$ (3294, Cell Signaling Technology, Danvers, MA), $\beta$-actin (5125, Cell Signaling), ATF6 (66563-1-Ig, Proteintech, Rosemont, IL), TAP1 (12341, Cell Signaling) CHOP (2895, Cell Signaling), ATF4 (11815, Cell Signaling), ovalbumin (P1-196, Thermo-Fisher), Myc tag (2272, Cell Signaling) and biotin (5597, Cell Signaling). IRE1 $\alpha$ lumenal domain, XBP1s and pIRE1 $\alpha$ antibodies were generated at Genentech. Secondary antibodies were (715-035-150, Jackson Laboratory, Bar Harbor, ME) for mouse and (711-035-152, Jackson Laboratory) for rabbit.

\section{Generation of TAP1 KO BMDCs}

Bone marrow cells were purified from Cas9-expressing C57BL/6 mice as described above, subjected to red blood cell lysis with ACK lysis buffer and electroporated with P3 Primary Cell 4D-Nucleaofactor ${ }^{\mathrm{TM}}$ X -kit (V4XP-3032, Lonza, Basel, Switzerland), as 
previously described (Freund et al., 2020). Once re-suspended in P3 buffer, cells were added a Cas9-ribonuceloprotein (RNP) complex (IDT) containing non-targeting or TAP1-targeting single guide RNAs (sgRNAs) (IDT). The sequences of TAP1-targeting sgRNA included: sgRNA A - GCGGCACCTCGGGAACCAAC, sgRNA B TAACTGATAGCGAAGGCATC, sgRNA C - ACGGCCGTGCATGTGTCCCA. These sgRNA were used separately or all three combined. Bone marrow cells were then transfected with the appropriate program and grown for 9 days similarly to all other BMDC cultures.

\section{In vitro IRE1 $\alpha$ LD binding assays}

For experiments testing ovalbumin binding, a human IRE1 $\alpha$-LD-Fc fusion protein (LDFc) was used at indicated concentrations. LD-Fc is comprised of amino acids M1-D443 of IRE $1 \alpha$ fused C-terminally to a linker (GRAQVTDKAARSTL) followed by the human IgG1 hinge and Fc portion. Ovalbumin (Sigma) was dissolved in sterile PBS and used in native state or denatured as indicated by incubation at $95^{\circ} \mathrm{C}$ or in $\mathrm{pH} 2.0$ or $\mathrm{pH} 10.0$ buffer for $10 \mathrm{~min}$.

For plate-based binding experiments, native or heat-denatured ovalbumin at indicated concentrations was bound to a flat-bottom 96 well plate (Corning Inc., Corning, NY) with coating buffer (Biolegend), washed with PBSt, blocked with $1 \%$ BSA in PBS and subsequently incubated with IRE1 $\alpha$ LD-Fc $(10 \mu \mathrm{g} / \mathrm{ml})$ in binding buffer composed of PBS with 20 mM HEPES, 100 mM KOAc and 0.2\% TWEEN-20 for 2 hrs at room temperature. Plates were washed again with PBSt and incubated with an antihuman Fc HRP-conjugated antibody (ab977225, Abcam). Development was performed 
with TMB solution and terminated with Stop solution (Biolegend). Readings were taken with a SpectraMax M2 spectrometer (Molecular Devices, San Jose, CA).

For co-immunoprecipitation experiments, IRE1 $\alpha$ LD-Fc $(10 \mu \mathrm{g} / \mathrm{ml})$ and ovalbumin (indicated concentrations) were co-incubated in binding buffer (as described above) for $2 \mathrm{hr}$ and then immunoprecipitated with anti-IRE1 $\alpha$ lumenal domain antibody (Genentech), conjugated to sepharose beads, overnight at $4^{\circ} \mathrm{C}$. Beads were subsequently washed four times with lysis buffer and boiled in SDS sample buffer for 10 min. Samples were then analyzed by SDS-PAGE followed by immunoblot.

Peptide arrays were produced by the MIT Biopolymers Laboratory. The tiling arrays were composed of 18-mer peptides spanning the ovalbumin or GP70 sequences and overlapping by 3 amino acids. The arrays were incubated in methanol for 10 min and then in binding buffer (50 mM Tris pH 7, $250 \mathrm{mM} \mathrm{NaCl}, 10 \%$ glycerol, 2 mM DTT) for three $10 \mathrm{~min}$ wash cycles. The arrays were then incubated for $1 \mathrm{hr}$ at room temperature with $500 \mathrm{nM}$ IRE1 $\alpha$ LD-Fc and washed again for three 10 min cycles in binding buffer to remove any unbound LD-Fc. Using a semi-dry transfer apparatus, bound IRE1 $\alpha$ LD-Fc was transferred after washes to a PVDF membrane and detected with anti-human Fc antibody (ab977225, Abcam), ECL solution (Thermo-Fisher) and ChemiDoc ZRS+ imager (Biorad). To measure binding of IRE1 $\alpha$ LD-Fc to each peptide, images containing developed membranes were quantified with ImageJ software (version 2.0.0). Pixel intensity was determined for all spots containing peptides, with background subtracted for spots containing no peptides. Peptides were considered to bind IRE1 $\alpha$ LD-Fc if spot intensity was above the average of all array peptides. 
For binding assays of biotin-tagged peptides, we generated a FLAG-tagged IRE1a lumenal domain (LD-FLAG) comprised of amino acids M1-D443 of IRE1a fused Cterminally to a linker (GNS) followed by a Flag tag (DYKDDDDK). LD-FLAG was incubated with synthetic $\mathrm{N}$-terminal biotin-tagged peptides derived from ovalbumin in binding buffer (as described above) for $1.5 \mathrm{hr}$, cross-linked by $25 \mu \mathrm{M}$ DSS (ThermoFisher) for $1 \mathrm{hr}$ and subsequently incubated with $50 \mu \mathrm{M}$ Tris $(\mathrm{pH} 7.5)$ for $15 \mathrm{~min}$ to quench cross-linking. Samples were then analyzed by SDS-PAGE followed by antibiotin immunoblot.

\section{Transfection of ovalbumin-derived peptides and co-IP of Myc-tagged peptides}

\section{with IRE1 1}

U20S or HEK293 cells were transfected with the TransIT-XL reagent (Mirus Bio, Madison, $\mathrm{WI}$ ) with PRK-TK-Neo plasmids encoding for ovalbumin-derived peptides with a signal sequence (MGGTAARLGAVILFVVIVGLHGVRG - based on the signal sequence of Human Herpes Virus 1 Glycoprotein D, with an added lysine residue to allow signal sequence processing upon translation), a flexible linker (DLGSSG) prior to the peptide sequence, and an N-terminal Myc tag (EQKLISEE). For immunoprecipitation or real-time quantitative PCR (RT-qPCR) analysis experiments, cells were harvested $48 \mathrm{hr}$ after transfection, washed twice with cold PBS, and harvested in cold PBS with protease inhibitor (Roche, Basel, Switzerland). Cells were lysed for $20 \mathrm{~min}$ on ice in lysis buffer (30 mM Tris, pH7.5, $150 \mathrm{mM} \mathrm{NaCl}, 1 \%$ Triton X100). The lysates were cleared by centrifugation at $14,000 \mathrm{rpm}$ for $10 \mathrm{~min}$ and then incubated with anti-Myc (Thermo-Fisher) antibody-conjugated sepharose beads 
overnight at $4^{\circ} \mathrm{C}$. Beads were subsequently washed four times with lysis buffer and boiled in SDS sample buffer for $10 \mathrm{~min}$. Samples were then analyzed by SDS-PAGE followed by immunoblot.

\section{Real-time quantitative PCR assay of transcript abundance}

For RT-qPCR analysis, RNA was purified from BMDCs, HEK293 or U20S cells with the RNeasy Mini-kit (Qiagen, Hilden, Germany) and quantified with a NanoDrop 8000 spectrophotometer (Thermo-Fisher). Similar amounts of RNA were reverse transcribed and amplified using the Taqman ${ }^{\text {TM }}$ RNA-to-CT ${ }^{\mathrm{TM}}$ 1-Step kit (Applied Biosystems, Waltham, MA). The following Taqman probes were used for HEK293 or U20S-derived RNA: XBP1s (Hs03929085_g1), XBP1u (Hs028565596_m1), CD59 (Hs00174141_m1),

DGAT2 (Hs01045913_m1), and GAPDH (Hs02758991_g1) (Thermo-Fisher). The following Taqman probes were used for BMDC-derived RNA: H-2K (Mm01612247), CD59 (Mm00483149), DGAT2 (Mm0049536), BLOS1 (Mm00497168), RNF213 (Mm01248886), IRF7 (Mm00516793), $\beta$-2M (Mm00437762), TAP1 (Mm00443188), TAPBP (Mm00493417), ERAP1 (Mm00472842), and GAPDH (Mm99999915) (ThermoFisher). Assays were performed with the ViiA 7 (Applied Biosystems) system.

\section{In vitro degradation of MHC-I heavy-chain transcripts}

To search for IRE1 $\alpha$ cleavage sites within MHC-I heavy chain mRNAs, sequences were loaded unto A Plasmid Editor (APE) software and subjected to a search function for consensus GCAG locations. The location most likely to provide a stable stem-loop structure within each transcript was then chosen. 
To determine cleavage by IRE1 $\alpha$, T7 RNA transcripts were synthesized based on cDNA templates of H-2K (\#OMu17935, GenScript, Piscataway, NJ), H-2D (\#MC208623, Origene, Rockville, MD) and H-2L (\#MC227254, Origene). Amplification of cDNA was conducted using T7 forward primers and cDNA-based RNA was generated using HiScribe $^{T M}$ T7 Quick High-Yield RNA Synthesis kit (New England Biolabs, Ipswich, MA).

T7 RNA $(1 \mu \mathrm{g})$ was digested at room temperature by IRE1 $\alpha$ recombinant KR protein (1 $\mu \mathrm{g}$ ) for 15 min in RNA cleavage buffer (HEPES pH 7.5, 20mM, KOAc 50 mM, MGAc $1 \mathrm{mM}$, Tritox $\mathrm{X}-100 \mathrm{0.05 \% )}$. The digestion was terminated by addition of formamide (97\%) and exposed to $70^{\circ} \mathrm{C}$ temperature to linearize the RNA. Immediately after linearization, samples were placed on ice for 5 min and then run on a $3 \%$ agarose gel. Gels were visualized by a ChemiDoc ZRS+ imager (Biorad).

\section{Ex vivo T-cell activation and cross-presentation experiments}

For ex vivo T-cell activation experiments, mice were euthanized and spleens were removed and mechanically disrupted with a GentleMacs tissue dissociator (Miltenyi Biotec Inc, Auburn, CA). Total spleen cells were washed with sterile PBS, counted and $\mathrm{CD}^{+}$or $\mathrm{CD}^{+} \mathrm{T}$ cells were magnetically separated with appropriate separation kits (Stemcell Technologies, Vancouver, Canada).

For CD3/CD28-mediated activation, Ultra Low-endotoxin, Azide-Free (LEAF) plate-bound anti-mouse CD3 (Biolegend) was used at $2 \mu \mathrm{g} / \mathrm{ml}$ and soluble anti-mouse CD28 (Biolegend) was used at $8 \mu \mathrm{g} / \mathrm{ml}$. T cells were incubated for 72 hours prior to flow cytometry analysis or Cell Titer Glo (Promega) analysis. 
For antigen cross-presentation assays, $2 \cdot 10^{4}$ BMDCs were plated, activated with LPS $(10 \mu \mathrm{g} / \mathrm{ml})$ for 2 hours and pulsed with SIINFEKL (100 nM), ovalbumin, EFOVA, or CT26 lysate (all at $250 \mu \mathrm{g} / \mathrm{ml}$ ) overnight. BMDCs were then washed with media and $2 \cdot 10^{5} \mathrm{CD}^{+}$or $\mathrm{CD}^{+} \mathrm{T}$ cells were added and co-incubated for $72 \mathrm{hr}$ prior to flow cytometry analysis. T cells were stained with a Celltrace Violet Cell Proliferation reagent (Thermo-Fisher) prior to introduction to the co-culture. Proliferation was then determined by loss of Celltrace Violet signal in viable T cells after co-incubation.

\section{Mouse strains and in vivo tumor growth studies}

All animal procedures were approved and conformed to guidelines established by the Institutional Animal Care and Use Committee (IACUC) of Genentech and were carried out in facilities accredited by the Association for the Assessment and Accreditation of Laboratory Animal Care. In all in vivo studies, tumor size and body weight were measured twice per week. Subcutaneous and mammary fat pad tumor volumes were measured in two dimensions (length and width) using Ultra Cal-IV calipers (model 54 $10-111$; Fred V. Fowler Co.). The tumor volume was calculated using the following formula: tumor size $\left(\mathrm{mm}^{3}\right)=\left(\right.$ longer measurement $\times$ shorter measurement $\left.{ }^{2}\right) \times 0.5$. Tumor growth inhibition (TGI) as a percentage of vehicle was calculated as the percent difference between the daily average area under the tumor volume-time curve (AUC) of treatment and control group fits on the original untransformed scale over the same time period using the following formula: $\% \mathrm{TGI}=(1-[(\mathrm{AUC} / \mathrm{Day})$ Treatment $\div($ AUC/Day $)$ Vehicle]) 100. 
C57BL/6 and Balb/C mice were acquired from The Jackson Laboratory or from Charles River laboratories, and MyD88 KO mice were acquired from Charles River Laboratories (Wilmington, MA). For TAP1 KO experiments, in house-generated Cas9expressing C57BL/6 mice were used.

For CT26 and 4T1 tumor studies, mice were inoculated subcutaneously (s.c.) on the right flank. $1 \cdot 10^{5} \mathrm{CT} 26$ or 4 T1 cells were counted and suspended in HBSS (Gibco) and admixed with $50 \%$ Matrigel (BD) to a final volume of $100 \mu$ l. For EMT6 tumor studies, an identical number of cells was prepared similarly and inoculated into the mammary fat pad.

For in vivo studies, 7 days after tumor-cell inoculation animals were randomized into groups receiving vehicle control (50\% PEG400, 40\% water, 10\% DMSO) or G9668 (250 mg/kg) compound bidaily (BID) by oral gavage (PO). For the EMT6 combination studies, mice were randomized into four groups, with groups similarly receiving vehicle or G9668 in combination with anti-GP120 control antibody or 6E11 anti-PD-L1 antibody (both with LALAPG Fc alterations, dissolved in PBS, at $10 \mathrm{mg} / \mathrm{kg}$ intravenously (IV) for the first dose and $5 \mathrm{mg} / \mathrm{kg}$ intraperitoneally (IP) biweekly (BIW) thereafter).

\section{Flow cytometry}

For in vivo experiments, tumors were excised after euthanasia, mechanically disrupted by a GentleMacs tissue dissociator (Miltenyi Biotec Inc.) and enzymatically digested by dispase $(80 \mu \mathrm{g} / \mathrm{ml}$, Life Technologies, Carlsbad, CA), Collagenase $P$ (Roche, $20 \mu \mathrm{g} / \mathrm{ml}$ ) and DNAse I (Roche, $10 \mu \mathrm{g} / \mathrm{ml})$. For cytokine staining assays, cells were re-suspended in RPMI1640 growth media supplemented with T cell stimulation cocktail (4975-03, 
eBioscience Inc., San Diego, CA) and brefeldin A (Biolegend) and incubated at $37^{\circ} \mathrm{C}$ for $4 \mathrm{hr}$.

For flow cytometry analysis assays, samples were re-suspended in FACS buffer (0.5\% BSA, 0.05\% azide), blocked with anti-CD16/32 blocking antibodies (101302, Biolgend) for $20 \mathrm{~min}$ in $4^{\circ} \mathrm{C}$, and then incubated with fluorescently-labelled antibodies for a further $20 \mathrm{~min}$ in $4^{\circ} \mathrm{C}$. The following dyes were used: PI (Sigma), CellTrace Violet (Invitrogen, C34557) and Live/Dead Staining Kit (Invitrogen, L10119). The following antibodies were used: Perforin (PE, 12-9392-82, eBiosciences), ki67 (BV421, 652411), CD8 (PE-Cy7, 100722), CD4 (APC-Cy7, 100526), CD3 (APC, 100236), F4/80 (APCCy7, 123118), MHC Class I (FITC, 125508), MHC class II (BV605, 107639), CD11C (BV711, 117349), CD11b (APC, 101212), XCR1 (BV421, 148216), CD103 (AF488, 121408), granzyme B (FITC, 515403), CD59 (PE, 143103), PD-1 (BV605, 135220), CD44 (BV711, 103057), CD69 (PE-Cy7, 104512), IFN- $\gamma$ (APC, 505810) (all from Biolegend). The Foxp3 Fix/Perm Kit was used for intracellular staining (421403, Biolegend). GP70 tetramers were generated at Genentech, as described (Vormehr et al., 2020).

Samples were read in a BD Symphony cell analyzer (BD) and data was analyzed in FlowJo Software (FlowJo 10.2, FlowJo LLC, Ashland, OR). For cell sorting, a BD FACSAria II (BD, Franklin Lakes, NJ) was utilized.

\section{Single cell RNA sequencing}


For single cell RNA sequencing, libraries were generated using Chromium Single Cell 5'

Library \& Gel Bead kit (1000006, 10X Genomics, Pleasanton, CA), from $2.5 \cdot 10^{4}$ viable

CD45 $5^{+}$cells sorted from $4 \mathrm{~T} 1$ tumors.

\section{Statistical analysis}

All values were represented as arithmetic mean \pm standard deviation (SD). Statistical analysis was performed by unpaired, two-tailed $t$ test or one-way ANOVA. A resulting P value $<0.05$ was considered significant. All analyses were performed with the GraphPad Prism 7 software (GraphPad Software, Inc., San Diego, CA). 
bioRxiv preprint doi: https://doi.org/10.1101/2021.09.10.459738; this version posted September 10, 2021. The copyright holder for this preprint (which was not certified by peer review) is the author/funder, who has granted bioRxiv a license to display the preprint in perpetuity. It is made available under aCC-BY 4.0 International license.

\section{AUTHOR CONTRIBUTIONS}

OG designed research studies, conducted experiments and wrote the manuscript. ALT, JMH, SMH, AM and GS designed research studies and conducted experiments. SM, DL conducted experiments. LG and TW analyzed data. ZM and IM designed research studies. AA designed research studies and wrote the manuscript. 


\section{ACKNOWLEDGEMENTS}

We thank Angela Yang for assistance with design, performance and analysis of singlecell RNA sequencing of tumor leukocytes; Marie-Gabrielle Braun and Joachim Rudolph for providing G9668; Maureen Beresini for kinome selectivity analysis; David Kan and Ehud Segal for help with design and performance of in vivo tumor studies and treatment with anti-PD-L1 antibodies; Shannon Ruppert, Jeanne Cheung, Shiuh Luoh, Yajun Chestnut and Manmeet Singh for assistance with harvesting of tumor-bearing mice; Christine Moussion, Shannon Turley, Mable Lam, and Peter Walter for helpful discussions. 
bioRxiv preprint doi: https://doi.org/10.1101/2021.09.10.459738; this version posted September 10, 2021. The copyright holder for this preprint (which was not certified by peer review) is the author/funder, who has granted bioRxiv a license to display the preprint in perpetuity. It is made available under aCC-BY 4.0 International license.

\section{COMPETING INTERESTS}

All authors are current or past employees of Genentech Inc. and have no other competing interests to declare. 


\section{REFERENCES}

Acosta-Alvear, D., Zhou, Y., Blais, A., Tsikitis, M., Lents, N. H., Arias, C., . . Dynlacht, B. D. (2007). XBP1 controls diverse cell type- and condition-specific transcriptional regulatory networks. Mol Cell, 27(1), 53-66. doi:10.1016/j.molcel.2007.06.011

Alloatti, A., Kotsias, F., Magalhaes, J. G., \& Amigorena, S. (2016). Dendritic cell maturation and cross-presentation: timing matters! Immunol Rev, 272(1), 97-108. doi:10.1111/imr.12432

Amin-Wetzel, N., Saunders, R. A., Kamphuis, M. J., Rato, C., Preissler, S., Harding, H. P., \& Ron, D. (2017). A J-Protein Co-chaperone Recruits BiP to Monomerize IRE1 and Repress the Unfolded Protein Response. Cell, 171(7), 1625-1637 e1613. doi:10.1016/j.cell.2017.10.040

Bae, D., Moore, K. A., Mella, J. M., Hayashi, S. Y., \& Hollien, J. (2019). Degradation of Blos 1 mRNA by IRE1 repositions lysosomes and protects cells from stress. J Cell Biol, 218(4), 1118-1127. doi:10.1083/jcb.201809027

Barber, D. L., Wherry, E. J., Masopust, D., Zhu, B., Allison, J. P., Sharpe, A. H., . . Ahmed, R. (2006). Restoring function in exhausted CD8 T cells during chronic viral infection. Nature, 439(7077), 682-687. doi:10.1038/nature04444

Barry, K. C., Hsu, J., Broz, M. L., Cueto, F. J., Binnewies, M., Combes, A. J., . . Krummel, M. F. (2018). A natural killer-dendritic cell axis defines checkpoint therapy-responsive tumor microenvironments. Nat Med, 24(8), 1178-1191. doi:10.1038/s41591-018-0085-8

Bertolotti, A., Zhang, Y., Hendershot, L. M., Harding, H. P., \& Ron, D. (2000). Dynamic interaction of $\mathrm{BiP}$ and ER stress transducers in the unfolded-protein response. Nat Cell Biol, 2(6), 326-332. doi:10.1038/35014014

Brasel, K., De Smedt, T., Smith, J. L., \& Maliszewski, C. R. (2000). Generation of murine dendritic cells from flt3-ligand-supplemented bone marrow cultures. Blood, 96(9), 30293039. Retrieved from https://www.ncbi.nlm.nih.gov/pubmed/11049981

Brodsky, J. L. (2012). Cleaning up: ER-associated degradation to the rescue. Cell, 151(6), 11631167. doi:10.1016/j.cell.2012.11.012

Calfon, M., Zeng, H., Urano, F., Till, J. H., Hubbard, S. R., Harding, H. P., . . Ron, D. (2002). IRE1 couples endoplasmic reticulum load to secretory capacity by processing the XBP-1 mRNA. Nature, 415(6867), 92-96. doi:10.1038/415092a

Chang, T. K., Lawrence, D. A., Lu, M., Tan, J., Harnoss, J. M., Marsters, S. A., . . Ashkenazi, A. (2018). Coordination between Two Branches of the Unfolded Protein Response Determines Apoptotic Cell Fate. Mol Cell, 71(4), 629-636 e625. doi:10.1016/j.molcel.2018.06.038

Chen, D. S., \& Mellman, I. (2013). Oncology meets immunology: the cancer-immunity cycle. Immunity, 39(1), 1-10. doi:10.1016/j.immuni.2013.07.012

Chen, J., Brunner, A. D., Cogan, J. Z., Nunez, J. K., Fields, A. P., Adamson, B., . . Weissman, J. S. (2020). Pervasive functional translation of noncanonical human open reading frames. Science, 367(6482), 1140-1146. doi:10.1126/science.aay0262

Chen, X., Iliopoulos, D., Zhang, Q., Tang, Q., Greenblatt, M. B., Hatziapostolou, M., . . . Glimcher, L. H. (2014). XBP1 promotes triple-negative breast cancer by controlling the HIF 1alpha pathway. Nature, 508(7494), 103-107. doi:10.1038/nature13119 
Chen, Z., Moyana, T., Saxena, A., Warrington, R., Jia, Z., \& Xiang, J. (2001). Efficient antitumor immunity derived from maturation of dendritic cells that had phagocytosed apoptotic/necrotic tumor cells. Int J Cancer, 93(4), 539-548. doi:10.1002/ijc. 1365

Cheng, S., Li, Z., Gao, R., Xing, B., Gao, Y., Yang, Y., .. . Zhang, Z. (2021). A pan-cancer single-cell transcriptional atlas of tumor infiltrating myeloid cells. Cell, 184(3), 792-809 e723. doi:10.1016/j.cell.2021.01.010

Cox, J. S., Shamu, C. E., \& Walter, P. (1993). Transcriptional induction of genes encoding endoplasmic reticulum resident proteins requires a transmembrane protein kinase. Cell, 73(6), 1197-1206. doi:10.1016/0092-8674(93)90648-a

Cross, B. C., Bond, P. J., Sadowski, P. G., Jha, B. K., Zak, J., Goodman, J. M., . . Harding, H. P. (2012). The molecular basis for selective inhibition of unconventional mRNA splicing by an IRE1-binding small molecule. Proc Natl Acad Sci U S A, 109(15), E869-878. doi:10.1073/pnas.1115623109

Cubillos-Ruiz, J. R., Silberman, P. C., Rutkowski, M. R., Chopra, S., Perales-Puchalt, A., Song, M., ... Glimcher, L. H. (2015). ER Stress Sensor XBP1 Controls Anti-tumor Immunity by Disrupting Dendritic Cell Homeostasis. Cell, 161(7), 1527-1538.

doi:10.1016/j.cell.2015.05.025

Dufey, E., Bravo-San Pedro, J. M., Eggers, C., Gonzalez-Quiroz, M., Urra, H., Sagredo, A. I., . . . Hetz, C. (2020). Genotoxic stress triggers the activation of IRE1alpha-dependent RNA decay to modulate the DNA damage response. Nat Commun, 11(1), 2401. doi:10.1038/s41467-020-15694-y

Fernandez, N. C., Lozier, A., Flament, C., Ricciardi-Castagnoli, P., Bellet, D., Suter, M., .. . Zitvogel, L. (1999). Dendritic cells directly trigger NK cell functions: cross-talk relevant in innate anti-tumor immune responses in vivo. Nat Med, 5(4), 405-411. doi: $10.1038 / 7403$

Freund, E. C., Lock, J. Y., Oh, J., Maculins, T., Delamarre, L., Bohlen, C. J., . . Murthy, A. (2020). Efficient gene knockout in primary human and murine myeloid cells by non-viral delivery of CRISPR-Cas9. J Exp Med, 217(7). doi:10.1084/jem.20191692

Gardner, B. M., \& Walter, P. (2011). Unfolded proteins are Ire1-activating ligands that directly induce the unfolded protein response. Science, 333(6051), 1891-1894. doi:10.1126/science.1209126

Garris, C. S., Arlauckas, S. P., Kohler, R. H., Trefny, M. P., Garren, S., Piot, C., . . Pittet, M. J. (2018). Successful Anti-PD-1 Cancer Immunotherapy Requires T Cell-Dendritic Cell Crosstalk Involving the Cytokines IFN-gamma and IL-12. Immunity, 49(6), 1148-1161 e1147. doi:10.1016/j.immuni.2018.09.024

Gatti, E., \& Pierre, P. (2003). Understanding the cell biology of antigen presentation: the dendritic cell contribution. Curr Opin Cell Biol, 15(4), 468-473. doi:10.1016/s09550674(03)00069-3

Harnoss, J. M., Le Thomas, A., Reichelt, M., Guttman, O., Wu, T. D., Marsters, S. A., . . Ashkenazi, A. (2020). IRE1alpha disruption in triple-negative breast cancer cooperates with anti-angiogenic therapy by reversing ER stress adaptation and remodeling the tumor microenvironment. Cancer Res. doi:10.1158/0008-5472.CAN-19-3108

Harnoss, J. M., Le Thomas, A., Shemorry, A., Marsters, S. A., Lawrence, D. A., Lu, M., . . . Ashkenazi, A. (2019). Disruption of IRE1alpha through its kinase domain attenuates multiple myeloma. Proc Natl Acad Sci U S A, 116(33), 16420-16429.

doi:10.1073/pnas.1906999116 
Harrington, P. E., Biswas, K., Malwitz, D., Tasker, A. S., Mohr, C., Andrews, K. L., ... Lipford, J. R. (2015). Unfolded Protein Response in Cancer: IRE1alpha Inhibition by Selective Kinase Ligands Does Not Impair Tumor Cell Viability. ACS Med Chem Lett, 6(1), 68-72. doi: $10.1021 / \mathrm{ml} 500315 \mathrm{~b}$

Hetz, C. (2012). The unfolded protein response: controlling cell fate decisions under ER stress and beyond. Nat Rev Mol Cell Biol, 13(2), 89-102. doi:10.1038/nrm3270

Hollien, J. (2013). Evolution of the unfolded protein response. Biochim Biophys Acta, 1833(11), 2458-2463. doi:10.1016/j.bbamcr.2013.01.016

Hollien, J., Lin, J. H., Li, H., Stevens, N., Walter, P., \& Weissman, J. S. (2009). Regulated Ire1dependent decay of messenger RNAs in mammalian cells. J Cell Biol, 186(3), 323-331. doi:10.1083/jcb.200903014

Hollien, J., \& Weissman, J. S. (2006). Decay of endoplasmic reticulum-localized mRNAs during the unfolded protein response. Science, 313(5783), 104-107. doi:10.1126/science.1129631

Holst, C. R., Bou-Reslan, H., Gore, B. B., Wong, K., Grant, D., Chalasani, S., . . Ashkenazi, A. (2007). Secreted sulfatases Sulf1 and Sulf2 have overlapping yet essential roles in mouse neonatal survival. PLoS One, 2(6), e575. doi:10.1371/journal.pone.0000575

Hooks, K. B., \& Griffiths-Jones, S. (2011). Conserved RNA structures in the non-canonical Hac1/Xbp1 intron. RNA Biol, 8(4), 552-556. doi:10.4161/rna.8.4.15396

Iwakoshi, N. N., Pypaert, M., \& Glimcher, L. H. (2007). The transcription factor XBP-1 is essential for the development and survival of dendritic cells. J Exp Med, 204(10), 22672275. doi:10.1084/jem.20070525

Jansen, C. S., Prokhnevska, N., Master, V. A., Sanda, M. G., Carlisle, J. W., Bilen, M. A., .. . Kissick, H. (2019). An intra-tumoral niche maintains and differentiates stem-like CD8 T cells. Nature, 576(7787), 465-470. doi:10.1038/s41586-019-1836-5

Jhunjhunwala, S., Hammer, C., \& Delamarre, L. (2021). Antigen presentation in cancer: insights into tumour immunogenicity and immune evasion. Nat Rev Cancer. doi:10.1038/s41568021-00339-z

Jurkin, J., Henkel, T., Nielsen, A. F., Minnich, M., Popow, J., Kaufmann, T., . . Martinez, J. (2014). The mammalian tRNA ligase complex mediates splicing of XBP1 mRNA and controls antibody secretion in plasma cells. EMBO J, 33(24), 2922-2936. doi:10.15252/embj.201490332

Karagoz, G. E., Acosta-Alvear, D., Nguyen, H. T., Lee, C. P., Chu, F., \& Walter, P. (2017). An unfolded protein-induced conformational switch activates mammalian IRE1. Elife, 6. doi:10.7554/eLife. 30700

Koivusalo, M., Welch, C., Hayashi, H., Scott, C. C., Kim, M., Alexander, T., . . Grinstein, S. (2010). Amiloride inhibits macropinocytosis by lowering submembranous $\mathrm{pH}$ and preventing Rac1 and Cdc42 signaling. J Cell Biol, 188(4), 547-563. doi:10.1083/jcb.200908086

Korennykh, A. V., Egea, P. F., Korostelev, A. A., Finer-Moore, J., Zhang, C., Shokat, K. M., ... Walter, P. (2009). The unfolded protein response signals through high-order assembly of Ire1. Nature, 457(7230), 687-693. doi:10.1038/nature07661

Kosmaczewski, S. G., Edwards, T. J., Han, S. M., Eckwahl, M. J., Meyer, B. I., Peach, S., . . . Hammarlund, M. (2014). The RtcB RNA ligase is an essential component of the metazoan unfolded protein response. EMBO Rep, 15(12), 1278-1285.

doi:10.15252/embr.201439531 
Lam, M., Marsters, S. A., Ashkenazi, A., \& Walter, P. (2020). Misfolded proteins bind and activate death receptor 5 to trigger apoptosis during unresolved endoplasmic reticulum stress. Elife, 9. doi:10.7554/eLife.52291

Lee, A. H., Iwakoshi, N. N., \& Glimcher, L. H. (2003). XBP-1 regulates a subset of endoplasmic reticulum resident chaperone genes in the unfolded protein response. Mol Cell Biol, 23(21), 7448-7459. doi:10.1128/mcb.23.21.7448-7459.2003

Lee, K. P., Dey, M., Neculai, D., Cao, C., Dever, T. E., \& Sicheri, F. (2008). Structure of the dual enzyme Ire1 reveals the basis for catalysis and regulation in nonconventional RNA splicing. Cell, 132(1), 89-100. doi:10.1016/j.cell.2007.10.057

Lhomond, S., Avril, T., Dejeans, N., Voutetakis, K., Doultsinos, D., McMahon, M., ... Chevet, E. (2018). Dual IRE1 RNase functions dictate glioblastoma development. EMBO Mol Med, 10(3). doi:10.15252/emmm.201707929

Lu, M., Lawrence, D. A., Marsters, S., Acosta-Alvear, D., Kimmig, P., Mendez, A. S., . . . Ashkenazi, A. (2014). Opposing unfolded-protein-response signals converge on death receptor 5 to control apoptosis. Science, 345(6192), 98-101. doi:10.1126/science.1254312

Lu, Y., Liang, F. X., \& Wang, X. (2014). A synthetic biology approach identifies the mammalian UPR RNA ligase RtcB. Mol Cell, 55(5), 758-770. doi:10.1016/j.molcel.2014.06.032

Mariathasan, S., Turley, S. J., Nickles, D., Castiglioni, A., Yuen, K., Wang, Y., . . Powles, T. (2018). TGFbeta attenuates tumour response to PD-L1 blockade by contributing to exclusion of T cells. Nature, 554(7693), 544-548. doi:10.1038/nature25501

Marinelli, D., Mazzotta, M., Pizzuti, L., Krasniqi, E., Gamucci, T., Natoli, C., . . Vici, P. (2020). Neoadjuvant Immune-Checkpoint Blockade in Triple-Negative Breast Cancer: Current Evidence and Literature-Based Meta-Analysis of Randomized Trials. Cancers (Basel), 12(9). doi:10.3390/cancers12092497

Martinon, F., Chen, X., Lee, A. H., \& Glimcher, L. H. (2010). TLR activation of the transcription factor XBP1 regulates innate immune responses in macrophages. Nat Immunol, 11(5), 411-418. doi:10.1038/ni.1857

Maurel, M., Chevet, E., Tavernier, J., \& Gerlo, S. (2014). Getting RIDD of RNA: IRE1 in cell fate regulation. Trends Biochem Sci, 39(5), 245-254. doi:10.1016/j.tibs.2014.02.008

Medel, B., Costoya, C., Fernandez, D., Pereda, C., Lladser, A., Sauma, D., . . Osorio, F. (2018). IRE1alpha Activation in Bone Marrow-Derived Dendritic Cells Modulates Innate Recognition of Melanoma Cells and Favors CD8(+) T Cell Priming. Front Immunol, 9, 3050. doi:10.3389/fimmu.2018.03050

Mellman, I., \& Steinman, R. M. (2001). Dendritic cells: specialized and regulated antigen processing machines. Cell, 106(3), 255-258. doi:10.1016/s0092-8674(01)00449-4

Mendes, A., Gigan, J. P., Rodriguez Rodrigues, C., Choteau, S. A., Sanseau, D., Barros, D., . . . Pierre, P. (2021). Proteostasis in dendritic cells is controlled by the PERK signaling axis independently of ATF4. Life Sci Alliance, 4(2). doi:10.26508/lsa.202000865

Moore, K., \& Hollien, J. (2015). Ire1-mediated decay in mammalian cells relies on mRNA sequence, structure, and translational status. Mol Biol Cell, 26(16), 2873-2884. doi:10.1091/mbc.E15-02-0074

Moore, K. A., Plant, J. J., Gaddam, D., Craft, J., \& Hollien, J. (2013). Regulation of sumo mRNA during endoplasmic reticulum stress. PLoS One, 8(9), e75723. doi:10.1371/journal.pone.0075723 
Oikawa, D., Tokuda, M., Hosoda, A., \& Iwawaki, T. (2010). Identification of a consensus element recognized and cleaved by IRE1 alpha. Nucleic Acids Res, 38(18), 6265-6273. doi:10.1093/nar/gkq452

Osorio, F., Tavernier, S. J., Hoffmann, E., Saeys, Y., Martens, L., Vetters, J., . . Lambrecht, B. N. (2014). The unfolded-protein-response sensor IRE-1alpha regulates the function of CD8alpha+ dendritic cells. Nat Immunol, 15(3), 248-257. doi:10.1038/ni.2808

Palucka, K., Banchereau, J., \& Mellman, I. (2010). Designing vaccines based on biology of human dendritic cell subsets. Immunity, 33(4), 464-478. doi:10.1016/j.immuni.2010.10.007

Peschek, J., Acosta-Alvear, D., Mendez, A. S., \& Walter, P. (2015). A conformational RNA zipper promotes intron ejection during non-conventional XBP1 mRNA splicing. EMBO Rep, 16(12), 1688-1698. doi:10.15252/embr.201540955

Poncet, A. F., Bosteels, V., Hoffmann, E., Chehade, S., Rennen, S., Huot, L., . . Marion, S. (2021). The UPR sensor IRE1alpha promotes dendritic cell responses to control Toxoplasma gondii infection. EMBO Rep, 22(3), e49617. doi:10.15252/embr.201949617

Sallusto, F., Cella, M., Danieli, C., \& Lanzavecchia, A. (1995). Dendritic cells use macropinocytosis and the mannose receptor to concentrate macromolecules in the major histocompatibility complex class II compartment: downregulation by cytokines and bacterial products. $J$ Exp Med, 182(2), 389-400. doi:10.1084/jem.182.2.389

Shen, X., Ellis, R. E., Lee, K., Liu, C. Y., Yang, K., Solomon, A., . . Kaufman, R. J. (2001). Complementary signaling pathways regulate the unfolded protein response and are required for C. elegans development. Cell, 107(7), 893-903. doi:10.1016/s00928674(01)00612-2

Smith, M. H., Ploegh, H. L., \& Weissman, J. S. (2011). Road to ruin: targeting proteins for degradation in the endoplasmic reticulum. Science, 334(6059), 1086-1090. doi:10.1126/science.1209235

So, J. S., Hur, K. Y., Tarrio, M., Ruda, V., Frank-Kamenetsky, M., Fitzgerald, K., . . Lee, A. H. (2012). Silencing of lipid metabolism genes through IRE1alpha-mediated mRNA decay lowers plasma lipids in mice. Cell Metab, 16(4), 487-499. doi:10.1016/j.cmet.2012.09.004

Spranger, S., Luke, J. J., Bao, R., Zha, Y., Hernandez, K. M., Li, Y., . . Gajewski, T. F. (2016). Density of immunogenic antigens does not explain the presence or absence of the T-cellinflamed tumor microenvironment in melanoma. Proc Natl Acad Sci U S A, 113(48), E7759-E7768. doi:10.1073/pnas.1609376113

Steinman, R. M. (2007). Dendritic cells: understanding immunogenicity. Eur J Immunol, 37 Suppl 1, S53-60. doi:10.1002/eji.200737400

Takeda, J., Sato, Y., Kiyosawa, H., Mori, T., Yokoya, S., Irisawa, A., . . Wanaka, A. (2000). Anti-tumor immunity against CT26 colon tumor in mice immunized with plasmid DNA encoding beta-galactosidase fused to an envelope protein of endogenous retrovirus. Cell Immunol, 204(1), 11-18. doi:10.1006/cimm.2000.1691

Tang, C. H., Chang, S., Paton, A. W., Paton, J. C., Gabrilovich, D. I., Ploegh, H. L., . . Hu, C. C. (2018). Phosphorylation of IRE1 at S729 regulates RIDD in B cells and antibody production after immunization. $J$ Cell Biol, 217(5), 1739-1755. doi:10.1083/jcb.201709137 
Tavernier, S. J., Osorio, F., Vandersarren, L., Vetters, J., Vanlangenakker, N., Van Isterdael, G., . .. Janssens, S. (2017). Regulated IRE1-dependent mRNA decay sets the threshold for dendritic cell survival. Nat Cell Biol, 19(6), 698-710. doi:10.1038/ncb3518

Thomas, C., \& Tampe, R. (2017). Proofreading of Peptide-MHC Complexes through Dynamic Multivalent Interactions. Front Immunol, 8, 65. doi:10.3389/fimmu.2017.00065

Tirasophon, W., Welihinda, A. A., \& Kaufman, R. J. (1998). A stress response pathway from the endoplasmic reticulum to the nucleus requires a novel bifunctional protein kinase/endoribonuclease (Ire1p) in mammalian cells. Genes Dev, 12(12), 1812-1824. doi:10.1101/gad.12.12.1812

Travers, K. J., Patil, C. K., Wodicka, L., Lockhart, D. J., Weissman, J. S., \& Walter, P. (2000). Functional and genomic analyses reveal an essential coordination between the unfolded protein response and ER-associated degradation. Cell, 101(3), 249-258. doi:10.1016/s0092-8674(00)80835-1

Vormehr, M., Lehar, S., Kranz, L. M., Tahtinen, S., Oei, Y., Javinal, V., . . Tureci, O. (2020). Dexamethasone premedication suppresses vaccine-induced immune responses against cancer. Oncoimmunology, 9(1), 1758004. doi:10.1080/2162402X.2020.1758004

Walter, P., \& Ron, D. (2011). The unfolded protein response: from stress pathway to homeostatic regulation. Science, 334(6059), 1081-1086. doi:10.1126/science.1209038

Wang, M., \& Kaufman, R. J. (2016). Protein misfolding in the endoplasmic reticulum as a conduit to human disease. Nature, 529(7586), 326-335. doi:10.1038/nature17041

Yoshida, H., Matsui, T., Yamamoto, A., Okada, T., \& Mori, K. (2001). XBP1 mRNA is induced by ATF6 and spliced by IRE1 in response to ER stress to produce a highly active transcription factor. Cell, 107(7), 881-891. doi:10.1016/s0092-8674(01)00611-0 

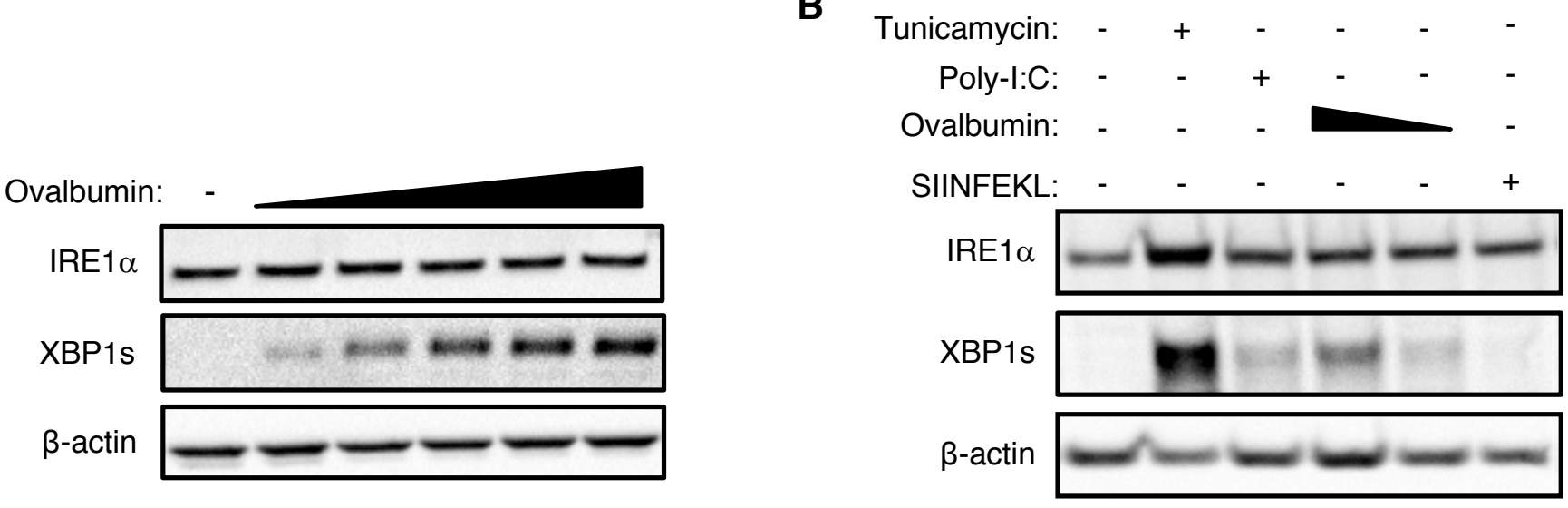

C

D
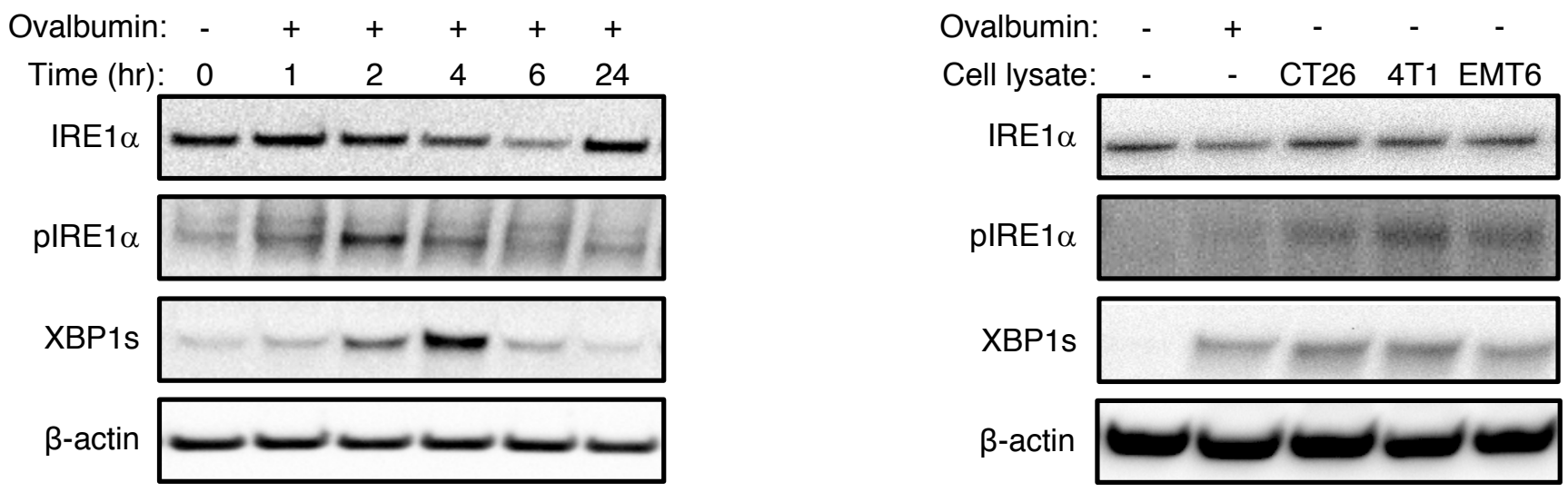

$\mathbf{E}$

F
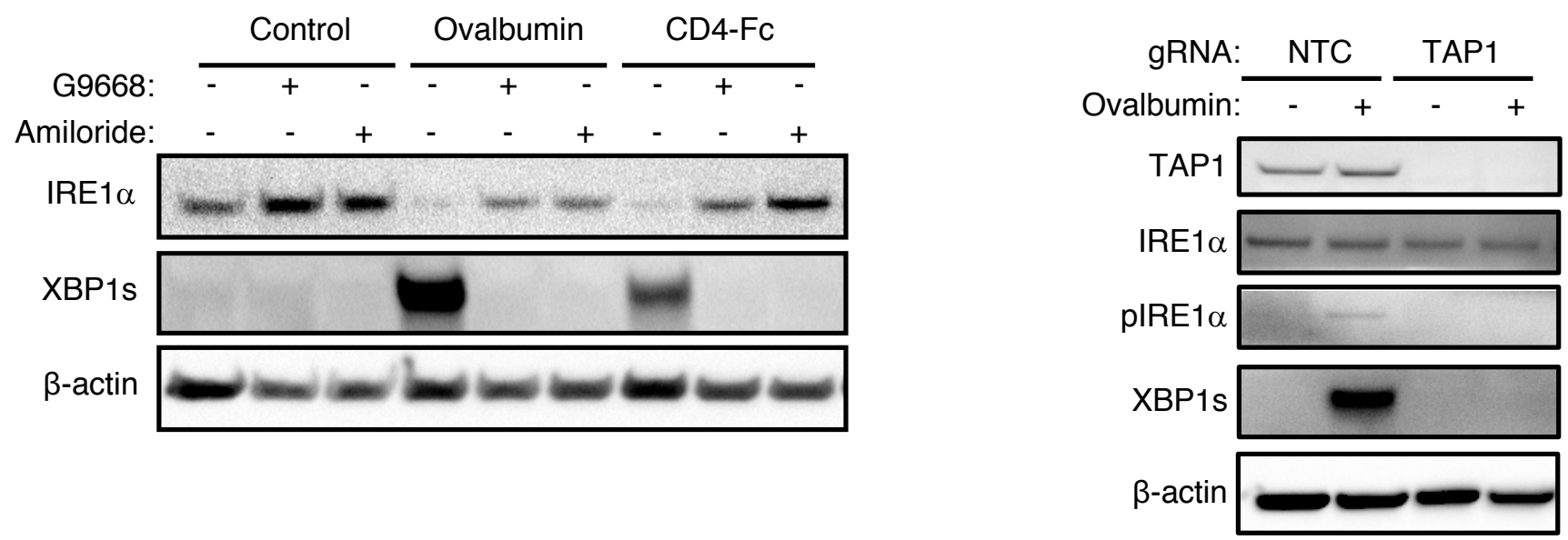

Figure 1. Antigen pulsing of BMDCs activates IRE1a. (A) BMDCs were pulsed with ovalbumin (starting at $62.5 \mu \mathrm{g} / \mathrm{ml}$ and sequentially doubled) and analyzed by immunoblot (IB) for the indicated markers. (B) BMDCs were pulsed with ovalbumin (starting at $500 \mathrm{\mu g} / \mathrm{ml}$ and sequentially halved) or SIINFEKL $(1 \mu \mathrm{M})$, or stimulated with tunicamycin $(1 \mu \mathrm{g} / \mathrm{ml})$ or poly-l:C $(25 \mu \mathrm{g} / \mathrm{ml})$ for $4 \mathrm{hr}$, and analyzed by IB. (C) BMDCs were pulsed with ovalbumin $(500 \mu \mathrm{g} / \mathrm{ml})$ for the indicated time and analyzed by IB. (D) BMDCs were pulsed for $4 \mathrm{hr}$ with ovalbumin or lysates derived from the indicated cell lines $(500 \mu \mathrm{g} / \mathrm{ml}$ protein) and analyzed by IB. (E) BMDCs were pulsed for $4 \mathrm{hr}$ with ovalbumin or human soluble CD4-Fc fusion protein (both at $500 \mu \mathrm{g} / \mathrm{ml})$, combined with DMSO or G9668 $(3 \mu \mathrm{M})$ or amiloride $(10 \mu \mathrm{M})$, and analyzed by IB. (F) Upon removal from bone marrow, total bone marrow cells were transfected with non-targeting control (NTC) or TAP1-targeting guide RNAs (gRNA), along with CRISPR/Cas9 delivery constructs. Cells were incubated in BMDC-differentiation media for 9 days, pulsed with ovalbumin ( $500 \mu \mathrm{g} / \mathrm{ml})$ for $4 \mathrm{hr}$, and analyzed by IB. All western blot images are representative of at least two similar experiments. 


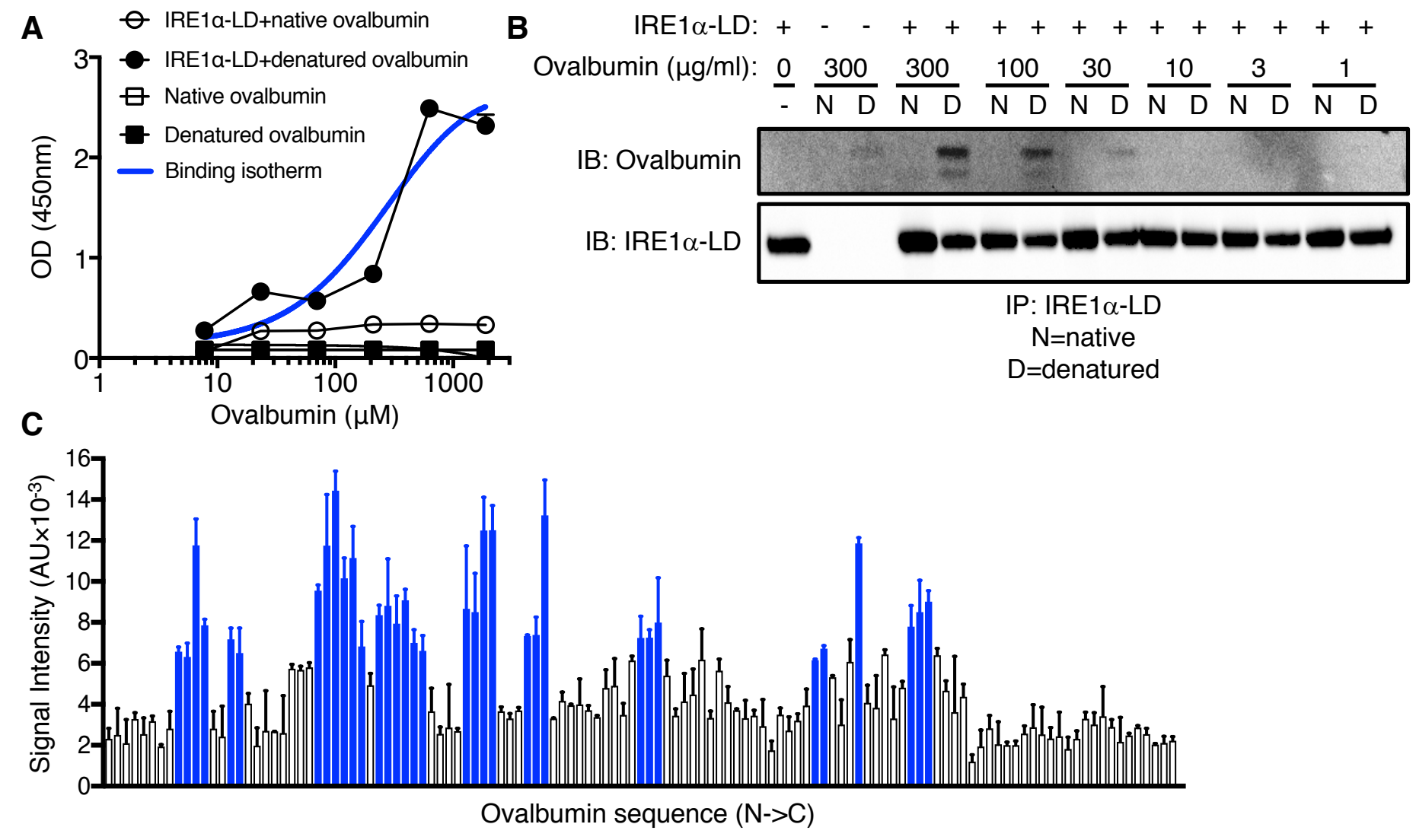

D

E IP: Myc

Biotin-Peptide: - $\quad$ B1 B1' B2 $\quad$ B2' B3

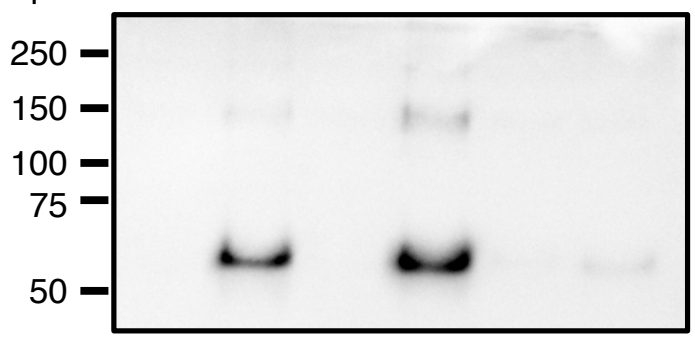

IB: Biotin
Myc-Peptide: - Vec M1 M2 M3

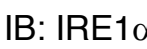
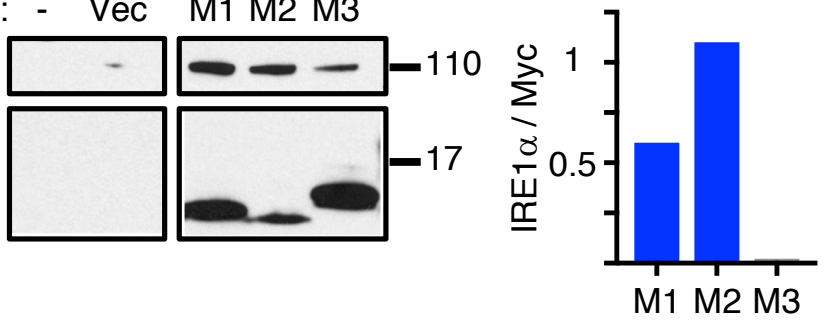

$\mathbf{F}$

疍

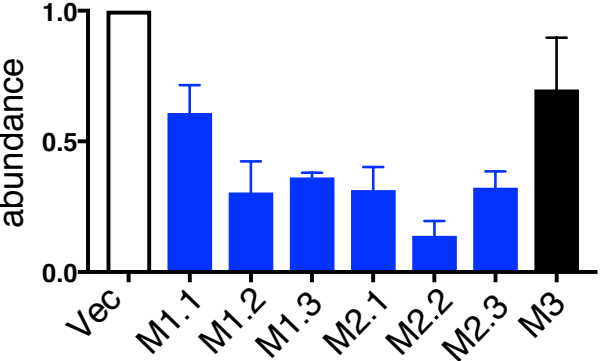

CD59

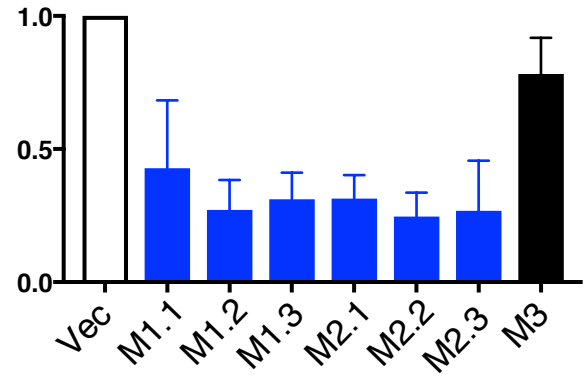

XBP1s/XBP1u

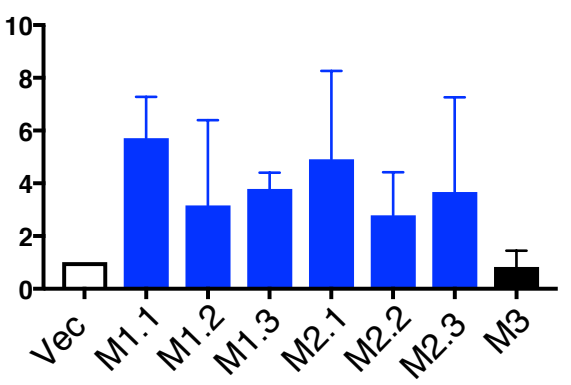

Figure 2. Antigen-derived peptides can directly engage IRE1 $\alpha$. (A) Polystyrene wells were coated with native or heat-denatured ovalbumin (10 $\mu \mathrm{g} / \mathrm{ml}$ ) and incubated with purified recombinant human IRE1 $\alpha$ LD-Fc fusion protein $(10 \mu \mathrm{g} / \mathrm{ml})$, followed by colorimetric detection with an HRPconjugated anti-human Fc antibody. (B) Native or heat-denatured ovalbumin at indicated concentrations was incubated with IRE1 $\alpha$ LD-Fc (10 $\mu \mathrm{g} / \mathrm{ml}$ ), immunoprecipitated via monoclonal anti-IRE $1 \alpha \mathrm{LD}$ antibody, and analyzed by IB. (C) A tiled 18 aa-long peptide array spanning ovalbumin was incubated with IRE1 $\alpha$ LD-Fc $(500 \mathrm{nM})$ followed by colorimetric detection with an HRP-conjugated anti-human Fc antibody. (D) Biotin-tagged ovalbumin-based peptides $(100 \mu \mathrm{M})$ were incubated with FLAG-tagged IRE1 $\alpha$ LD $(50 \mu \mathrm{M})$, cross-linked with disuccinimidyl suberate (DSS) and analyzed by IB. B1, B2, B3 are WT peptides; B1', B2' are mutant peptides in which all hydrophobic residues were replaced by aspartic acid. (E) HEK293 cells were transfected with cDNA constructs encoding Myc-tagged peptides (M1, M2, M3) derived from corresponding ovalbumin regions (B1, B2, B3) and containing an ER-directed signal sequence for $48 \mathrm{hr}$, followed by immunoprecipitation with anti-Myc antibody and IB for IRE1 $\alpha$ or Myc. Bar graph indicates signal ratio for IRE1 $\alpha$ over Myc. (F) U2OS cells were transfected with cDNA constructs encoding Myc-tagged peptides (M1.1, M1.2, M1.3, M2.1, M2.2, M2.3, M3) derived from corresponding ovalbumin regions (B1, B2, B3) and containing an ER-targeting signal sequence for $48 \mathrm{hr}$, followed by real-time quantitative PCR (RT-qPCR) analysis for XBP1s, XBP1u, CD59, and DGAT2 mRNA levels. Bar graphs in panels $\mathbf{A}, \mathbf{C}$ and $\mathbf{F}$ represent mean \pm SD from three independent technical repeats; images in panels $\mathbf{B}, \mathbf{D}$ and $\mathbf{E}$ represent at least two similar experiments. 


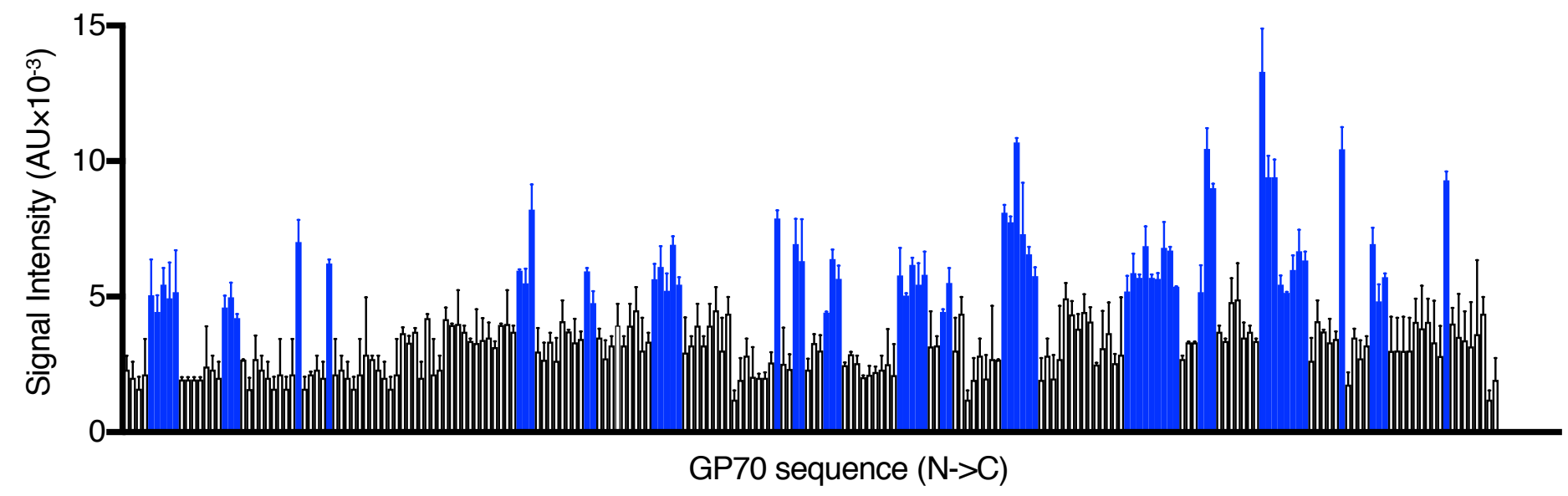

B
B1 SGLEQLESIINFEKLTEWTSSNVMEERKIK
B1' SGDEQDESDDNDEKDTEDTSSNDDEERKDK
M1
M1. 1
FEKLTEWTSSNVMEERKI
M1.2
LESIINFEKLTEWTSSNV
M1.3

\author{
IINFEKLTEWTSSNVMEE \\ FEKLTEWTSSNVMEERKI
}

$\begin{array}{ll}\text { B2 } & \text { ERKIKVYLPRMKMEEKYNLTSVLMAMGITD } \\ \text { B2 } & \text { ERKDKDDDPRDKDEEKDNLTSVLMAMGITD }\end{array}$

M2

M2 . 1

M2. 2

M2. 3

B3

QAVHAAHAEINEAGREVVGSAEAGVDAASV

M3

\author{
PRMKMEEKYNLTSVLMAM \\ VYLPRMKMEEKYNLTSVL \\ PRMKMEEKYNLTSVLMAM \\ KMEEKYNLTSVLMAMGIT
}

AVHAAHAEINEAGREVVG

Figure S2. Antigen-derived peptides can directly engage IRE1 $\alpha$. (A) A tiled 18 aa-long peptide array spanning GP70 was incubated with IRE1 $\alpha$ LD-Fc (500 nM) followed by colorimetric detection with an HRP-conjugated anti-human Fc antibody. (B) Sequences of biotin-tagged peptides (labeled B) used in Figure 1D; Myc-tagged signal peptides (labeled M) used in Fig. 2E; and Myc-tagged peptides (Labeled M) used in Figure 2F. Bar graphs in panel A represents mean \pm SD from three independent technical repeats. 

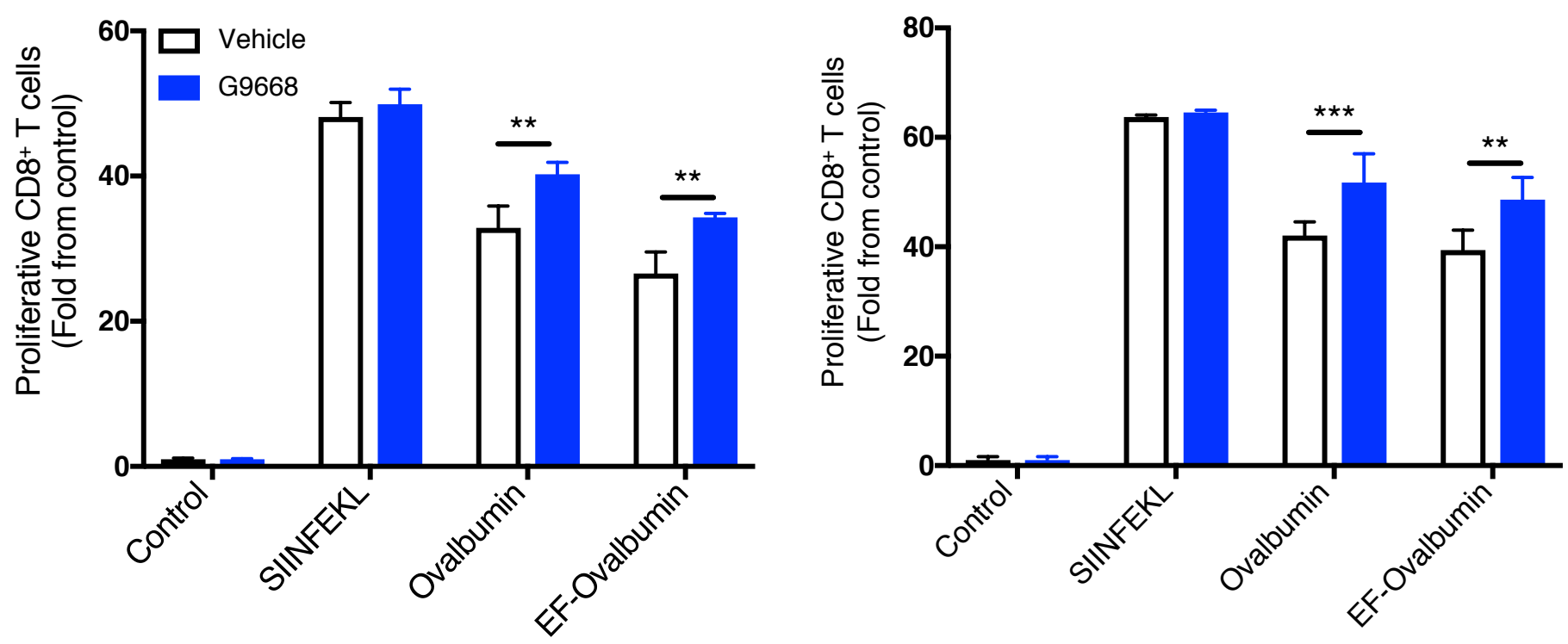

C
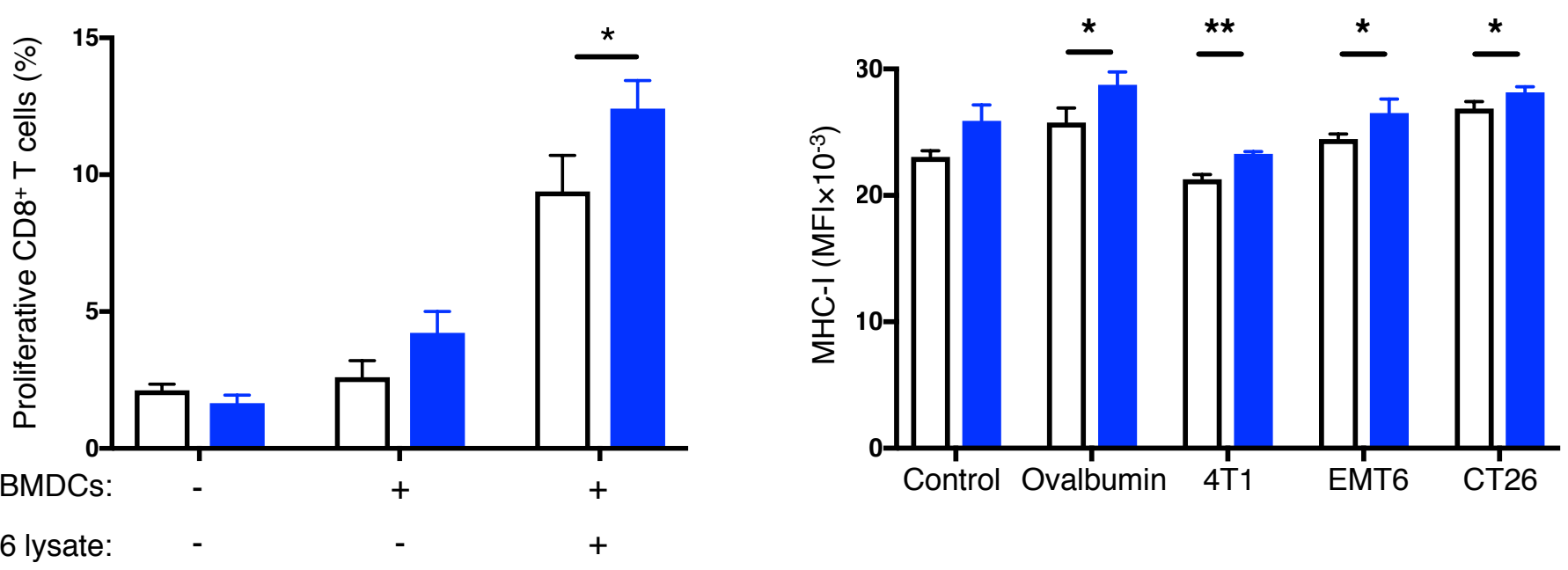

Figure 3. IRE1 $\alpha$ inhibition in BMDCs augments antigen cross-presentation to CD8+ $T$ cells. (A, B) GM-CSF+IL-4-matured (A) or Flt3L-matured (B) BMDCs were pulsed with ovalbumin $(500 \mu \mathrm{g} / \mathrm{ml})$ with or without G9668 $(3 \mu \mathrm{M})$ for $24 \mathrm{hr}$ and subsequently co-cultured with magneticallyseparated CD8+ OT-I T cells for $72 \mathrm{hr}$, followed by flow cytometry analysis of T cell proliferation by Celltrace Violet. (C) BMDCs were pulsed with lysates derived from CT26 cells $\left(500 \mu \mathrm{g} / \mathrm{ml}\right.$ protein) for $24 \mathrm{hr}$ and co-cultured with magnetically-separated CD8 ${ }^{+}$splenic T cells from CT26 tumorbearing mice for $72 \mathrm{hr}$, followed by analysis of T cell proliferation by flow cytometry of Celltrace Violet staining. (D) BMDCs were pulsed with ovalbumin or lysates derived from 4T1, EMT6 and CT26 cells $(500 \mu \mathrm{g} / \mathrm{ml}$ protein) for $8 \mathrm{hr}$ and surface levels of MHC-I were assayed by flow cytometry. Analysis was performed using unpaired, two-tailed $t$ test, ${ }^{*} \mathrm{P} \leq 0.05^{* *} \mathrm{P} \leq 0.01,{ }^{* * *} \mathrm{P} \leq 0.001$. Bar graphs in all panels represent mean \pm SD from three independent biological repeats; panels $\mathbf{A}$ and $\mathbf{B}$ represent data from at least independent experiments collated as fold from control for each experiment. 


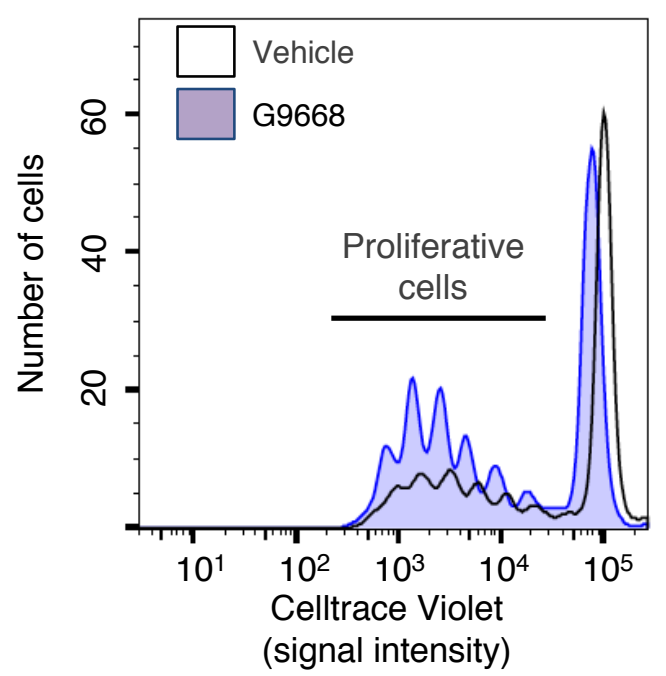

B
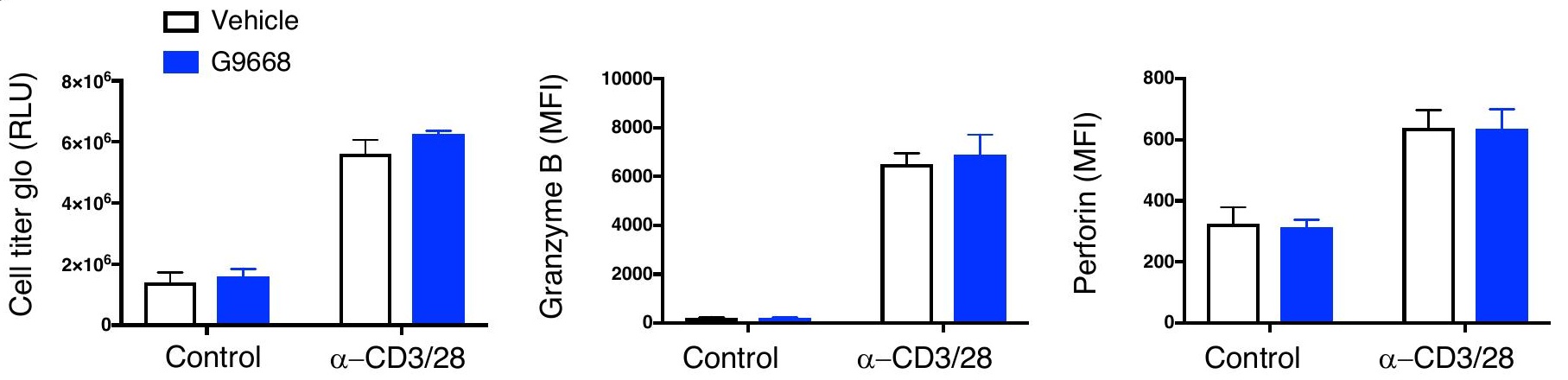

C

D
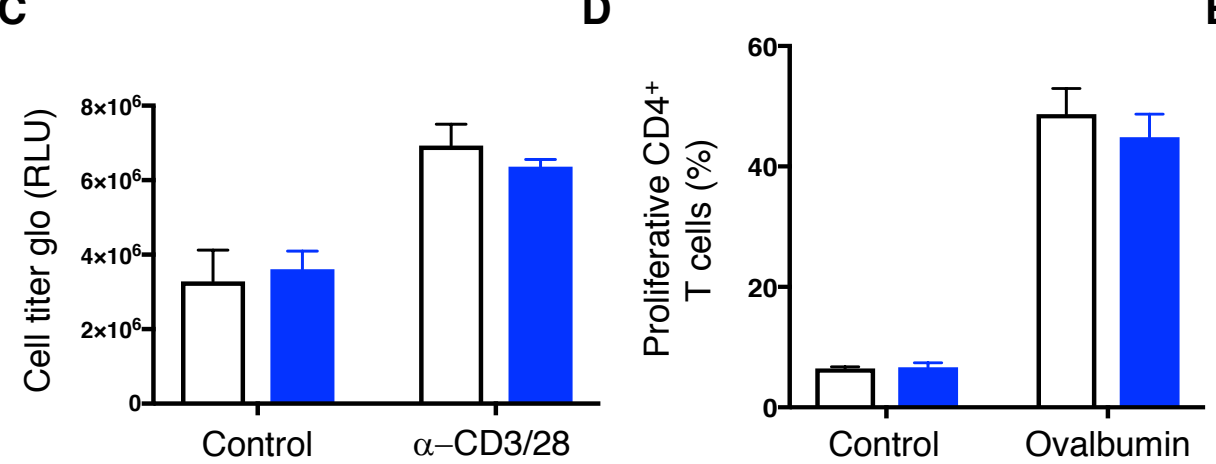

E

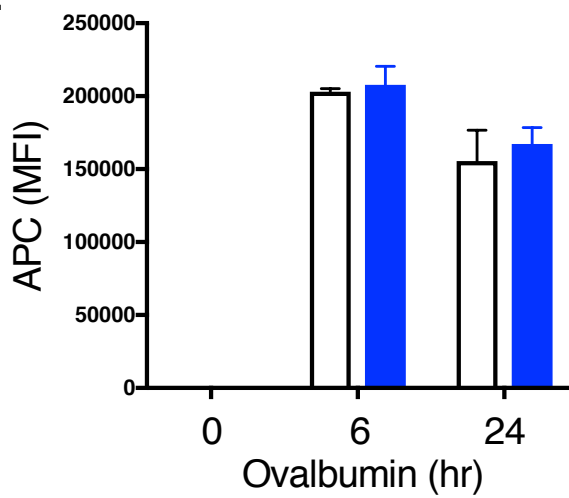

Figure S3. IRE1 $\alpha$ inhibition does not affect direct TCR-mediated activation of CD4+ and CD8+ T cells; MHC-II-restricted antigen presentation and soluble antigen uptake by BMDCs. (A) BMDCs matured as indicated were pulsed with ovalbumin (500 $\mu \mathrm{g} / \mathrm{ml}$ ) in absence or presence of G9668 (3 $\mu \mathrm{M})$ for $24 \mathrm{hr}$, and subsequently co-cultured with magnetically-separated CD4+ OT-I T cells for $72 \mathrm{hr}$, followed by flow cytometry analysis of T cell proliferation by Celltrace Violet. (B-D) Magnetically-separated CD8+ OT-I (B) or CD4+ OT-II (C) splenic T cells were activated by plate-bound anti-CD3 $(8 \mu \mathrm{g} / \mathrm{ml})$ and soluble anti-CD28 $(2 \mu \mathrm{g} / \mathrm{ml})$ antibodies in absence or presence of G9668 $(3 \mu \mathrm{M})$ for $72 \mathrm{hr}$. Proliferation and activation were analyzed respectively by Cell Titer Glo and flow cytometry. (D) BMDCs were pulsed with ovalbumin (500 $\mu \mathrm{g} / \mathrm{ml})$ for $24 \mathrm{hr}$, with or without G9668 (3 $\mu \mathrm{M})$ and subsequently co-cultured with magnetically-separated CD4+ OT-II T cells for 72 hr, followed by flow cytometry analysis of T cell proliferation by Celltrace Violet. (E) BMDCs were pulsed with APC-labelled ovalbumin (500 $\mu \mathrm{g} / \mathrm{ml})$ for indicated time and analyzed for internalization of ovalbumin by flow cytometry. (E) BMDCs were treated with G9668 (3 $\mu$ M) for 8 hr and mRNA levels of indicated genes associated with cross-presentation were analyzed by RT-qPCR. Bar graphs in panels B-E represent mean \pm SD from three independent biological repeats. 
B
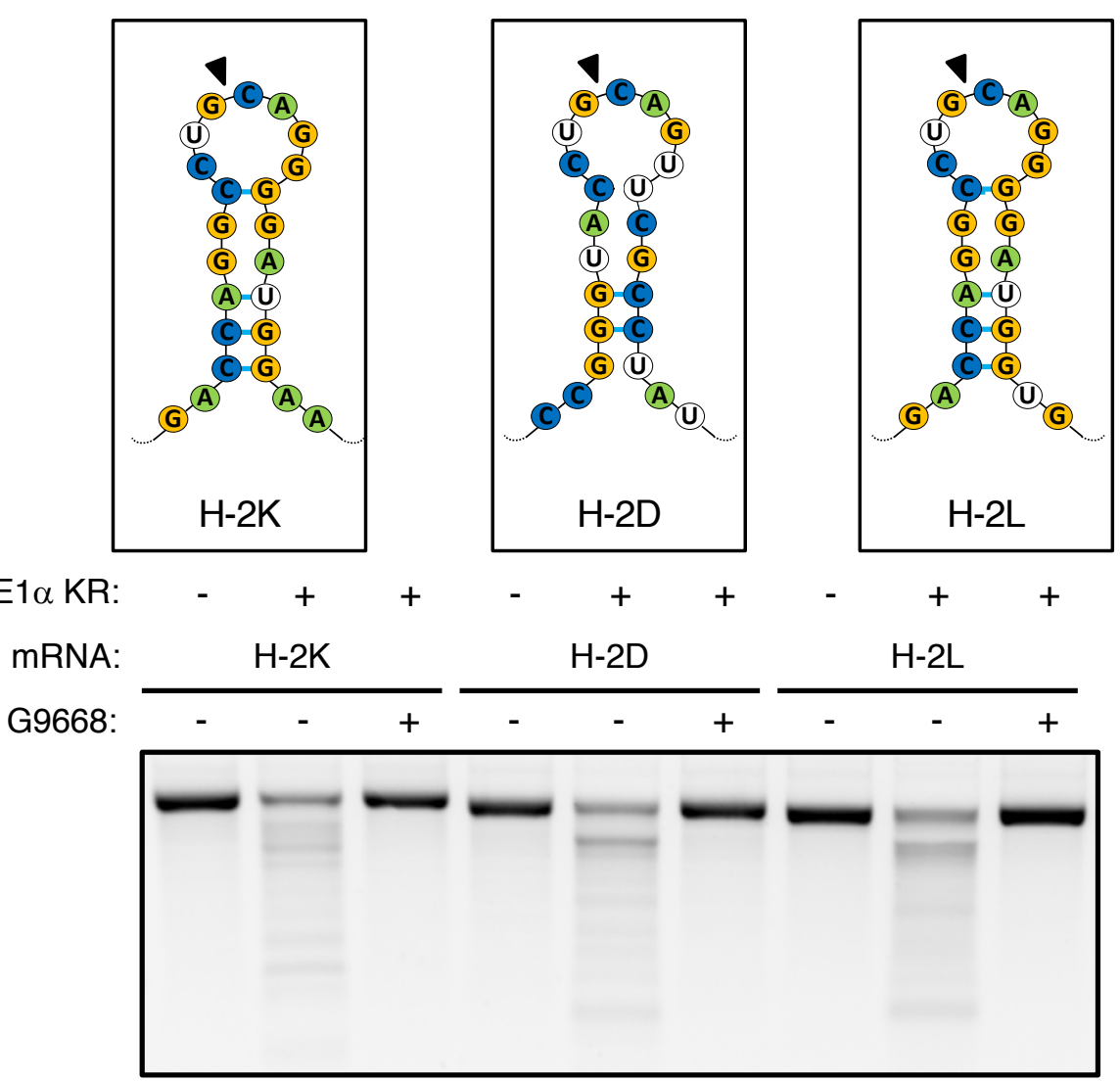

C
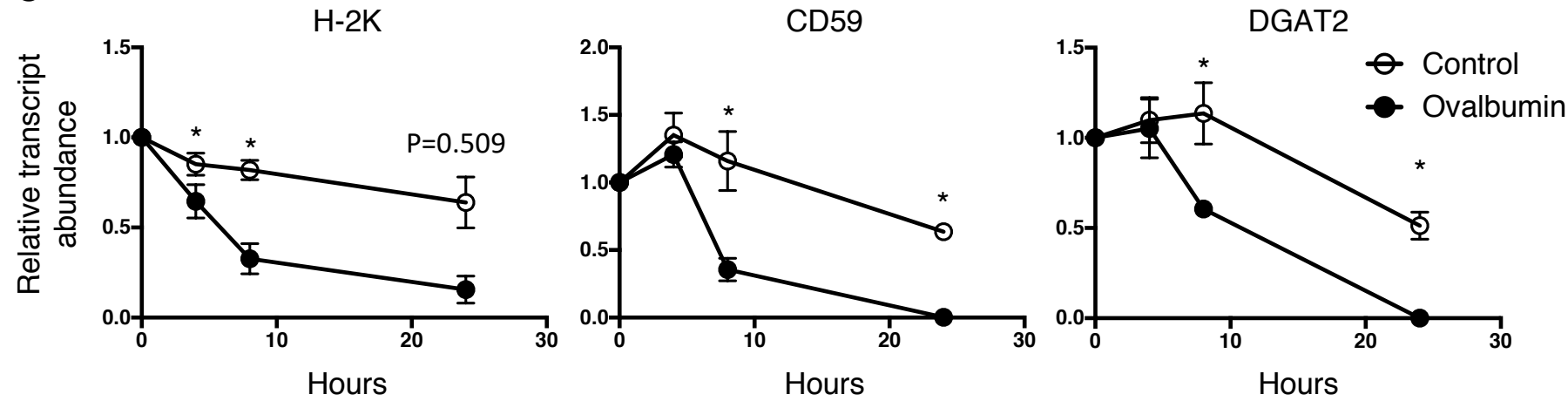

D

H-2K

옹

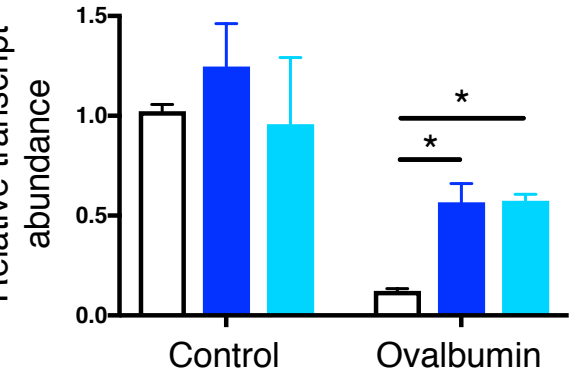

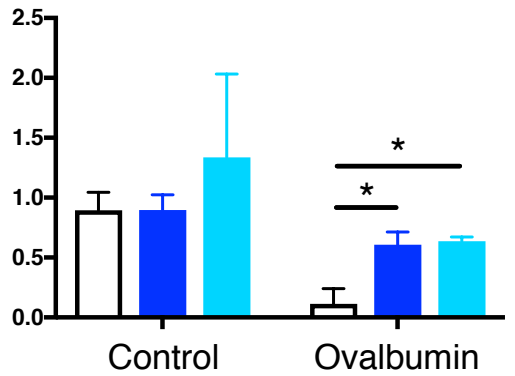

Vehicle

DGAT2

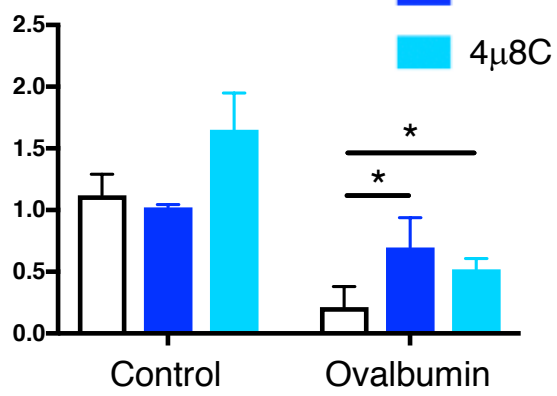

Figure 4. IRE1 $\alpha$ activation depletes MHC-I heavy-chain mRNAs via RIDD. (A) Consensus stem-loop endomotifs for RIDD recognition found in murine MHC-I heavy-chain $\mathrm{H}-2 \mathrm{~K}, \mathrm{H}-2 \mathrm{D}$ and $\mathrm{H}-2 \mathrm{~L}$ mRNA sequences. (B) Purified recombinant IRE1 $\alpha$ kinase-endoribonucleae (KR) protein was incubated with RNA transcripts of $\mathrm{H}-2 \mathrm{~K}, \mathrm{H}-2 \mathrm{D}$ and $\mathrm{H}-2 \mathrm{~L}$, in absence or presence of $\mathrm{G} 9668(10 \mu \mathrm{M})$, followed by agarose gel electrophoresis to determine transcript integrity. (C, D) BMDCs were treated with actinomycin D $(2 \mu \mathrm{g} / \mathrm{ml})$ to block de novo transcription and pulsed with ovalbumin $(500 \mu \mathrm{g} / \mathrm{ml})$ combined with DMSO, G9668 $(3 \mu \mathrm{M})$, or $4 \mu 8 \mathrm{C}(1 \mu \mathrm{M})$ for the indicated time period (C) or for $8 \mathrm{hr}(\mathrm{D})$, followed by RT-qPCR analysis of the indicated transcripts. Analysis was performed using unpaired, two-tailed $t$ test, ${ }^{*} \mathrm{P} \leq 0.05$. Panel $\mathrm{B}$ image represents three similar experiments; bar graphs in panels $\mathbf{C}$ and $\mathbf{D}$ represent mean \pm SD from three independent biological repeats. 
A

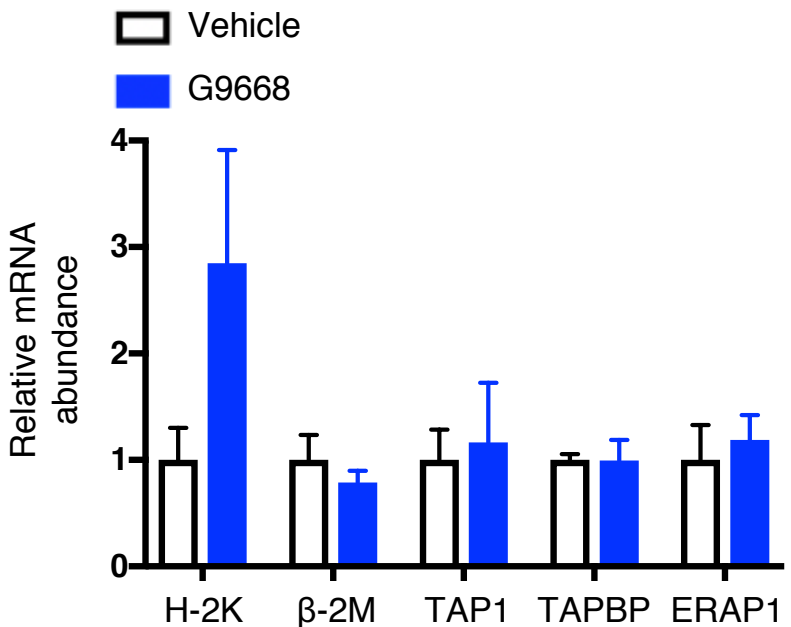

B

$\square$ Vehicle

G9668

$4 \mu 8 \mathrm{C}$

BLOS1

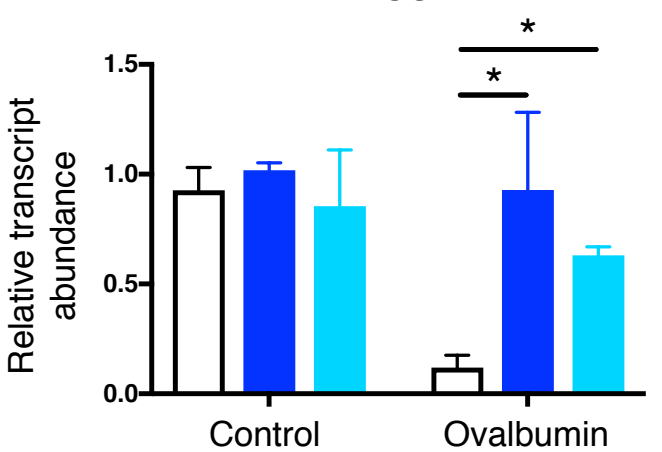

RNF213

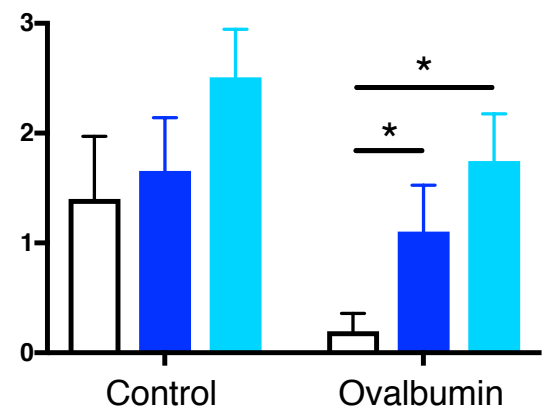

IRF7

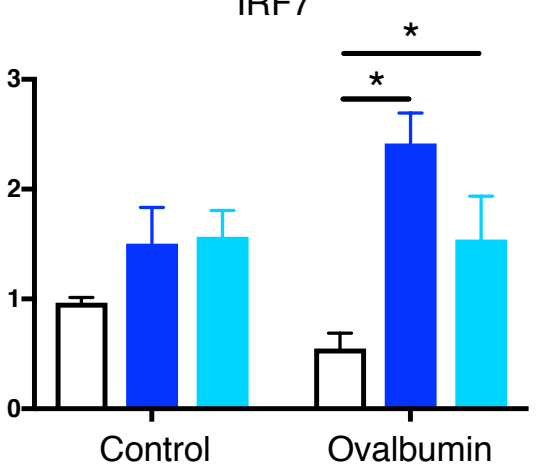

Figure S4. IRE1 $\alpha$ RIDD activity specifically targets MHC-I heavy-chain transcripts. (A) BMDCs were pulsed with ovalbumin (500 $\mu$ g/ml) for 8 hr in the absence or presence of G9668 $(3 \mu \mathrm{M})$, followed by real time RTqPCR measurements of the indicated RIDD substrates. (B) BMDCs were treated with actinomycin $\mathrm{D}(2 \mu \mathrm{g} / \mathrm{ml}))$ and pulsed with ovalbumin $(500 \mu \mathrm{g} / \mathrm{ml})$ for $8 \mathrm{hr}$ combined with DMSO or G9668 $(3 \mu \mathrm{M})$ or $4 \mu 8 \mathrm{C}(1 \mu \mathrm{g} / \mathrm{ml})$, followed by real time RTqPCR measurements of the indicated RIDD substrates. Analysis was performed using unpaired, two-tailed $t$ test, ${ }^{*} \mathrm{P} \leq$ 0.05. Bar graphs in all panels represent mean \pm SD from three independent technical repeats. 


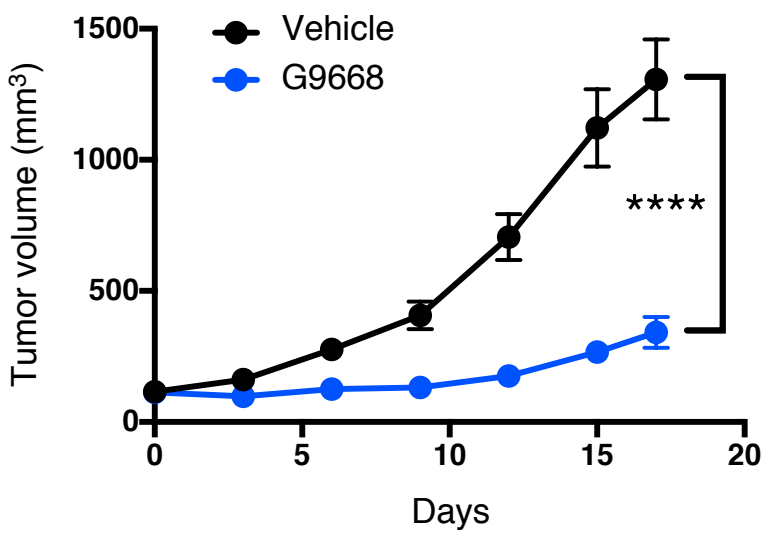

C

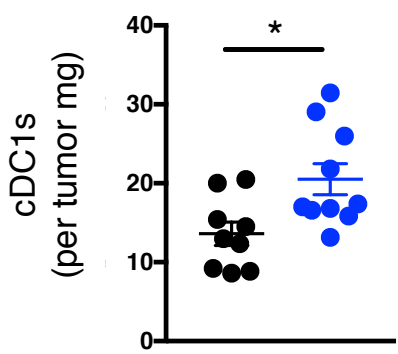

E
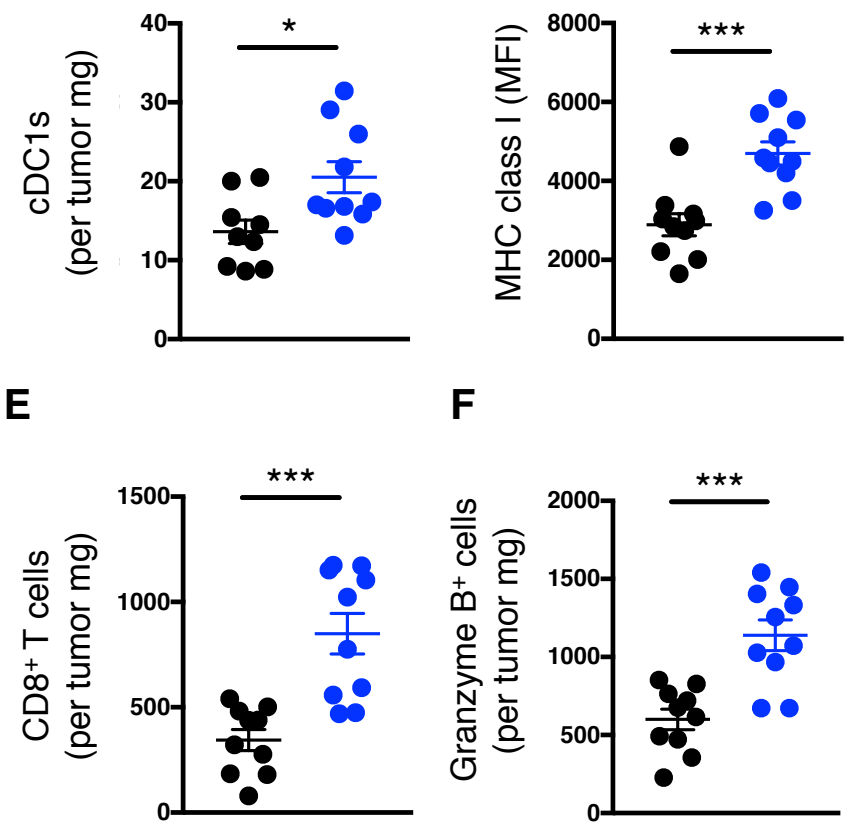

$\mathbf{F}$

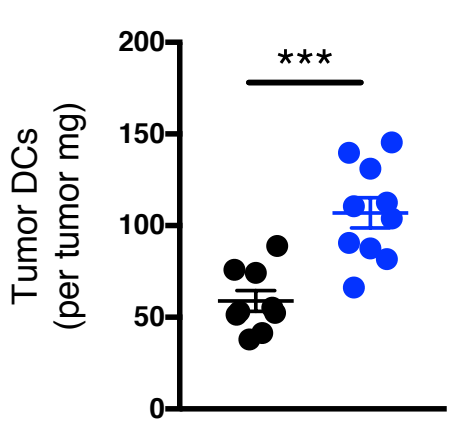

Vehicle

G9668

$\mathbf{G}$
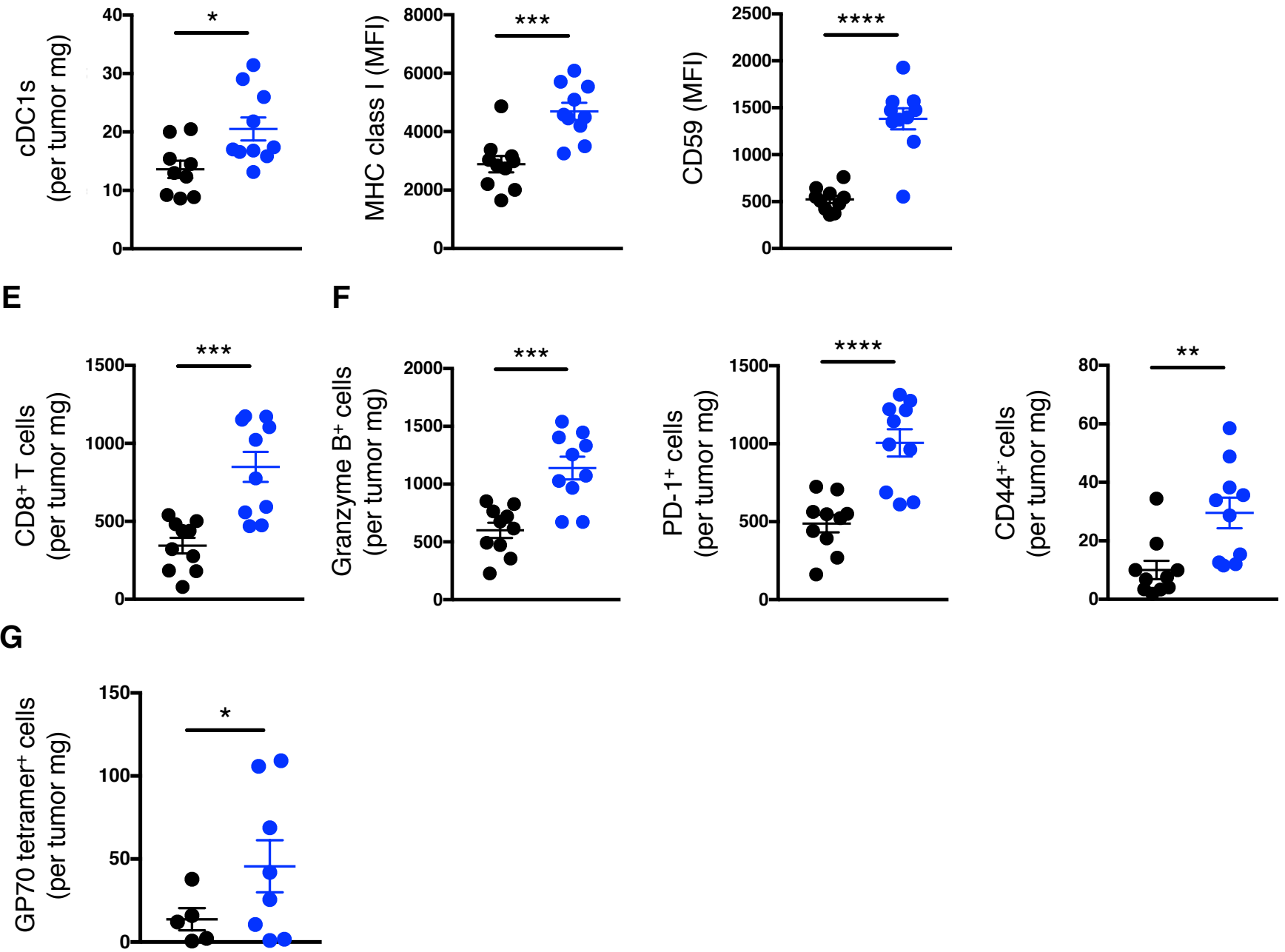

Figure 5. IRE1 $\alpha$ inhibition attenuates CT26 tumor growth in conjunction with enhanced MHC-I expression on tumor DCs and CD8+ T cell recruitment and activation. Mice were inoculated s.c. with CT26 cells, grouped out 7 days afterwards and treated with vehicle or G9668 (250 $\mathrm{mg} / \mathrm{kg}, \mathrm{BID})$. (A) Growth trajectories of CT26 tumors in vehicle- and G9668-treated animals over 17 days $(\mathrm{n}=15)$. (B-G) Flow cytometry analysis of tumor DCs and T cells from mice treated for 7 days. (B-D) Quantification of tumor-infiltrating total DCs (B) and CDC1s (C); and characterization of CDC1 expression of MHC-I and CD59 (D) by flow cytometry ( $n=9$ for vehicle-treated group and 10 for G9668-treate group). Total DCs were

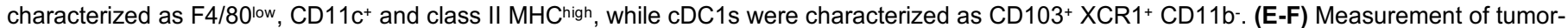
infiltrating $C D 8^{+}$T cell abundance $(E)$, expression of indicated activation markers $(F)(n=9$ for vehicle-treated group and 10 for $G 9668$-treate group), and binding of GP70 tetramers (G) ( $n=6$ for vehicle and 8 for G9668 group). Analysis was performed using one-way ANOVA for panel A and unpaired, two-tailed $t$ test for panels B-G, ${ }^{*} \mathrm{P} \leq 0.05{ }^{*} \mathrm{P} \leq 0.05,{ }^{* *} \mathrm{P} \leq 0.01,{ }^{* * *} \mathrm{P} \leq 0.001,{ }^{* * * *} \mathrm{P} \leq 0.0001$. Scatter plots in all panels represent mean $\pm S D$. 
A

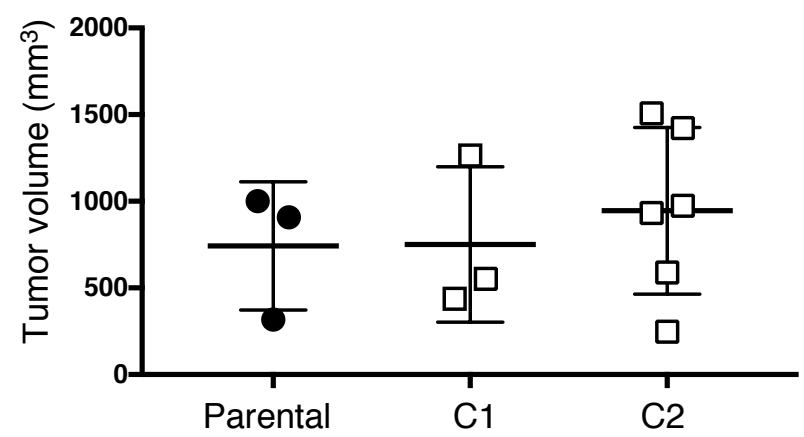

\begin{tabular}{|c|c|c|c|}
\hline Group & N & $\begin{array}{c}\% \text { TGI mean } \\
\text { (range) }\end{array}$ & $\begin{array}{c}\text { Mean tumor } \\
\text { size (range) }\end{array}$ \\
\hline $\begin{array}{c}\text { Parental } \\
\text { tumors }\end{array}$ & 8 & $0(0,0)$ & $\begin{array}{c}742(318, \\
1001)\end{array}$ \\
\hline $\begin{array}{c}\text { IRE1 } \alpha \text { KO } \\
\text { tumors }(\mathrm{C} 1)\end{array}$ & 5 & $19(-2,27)$ & $\begin{array}{c}751(437, \\
1264)\end{array}$ \\
\hline $\begin{array}{c}\text { IRE1 } \alpha \text { KO } \\
\text { tumors }(\mathrm{C} 2)\end{array}$ & 8 & $-3(-11,5)$ & $\begin{array}{c}945(247, \\
1507)\end{array}$ \\
\hline
\end{tabular}

IRE1 $\alpha \mathrm{KO} \quad$ IRE1 $\alpha \mathrm{KO}$

$(\mathrm{C} 1)$ (C2)
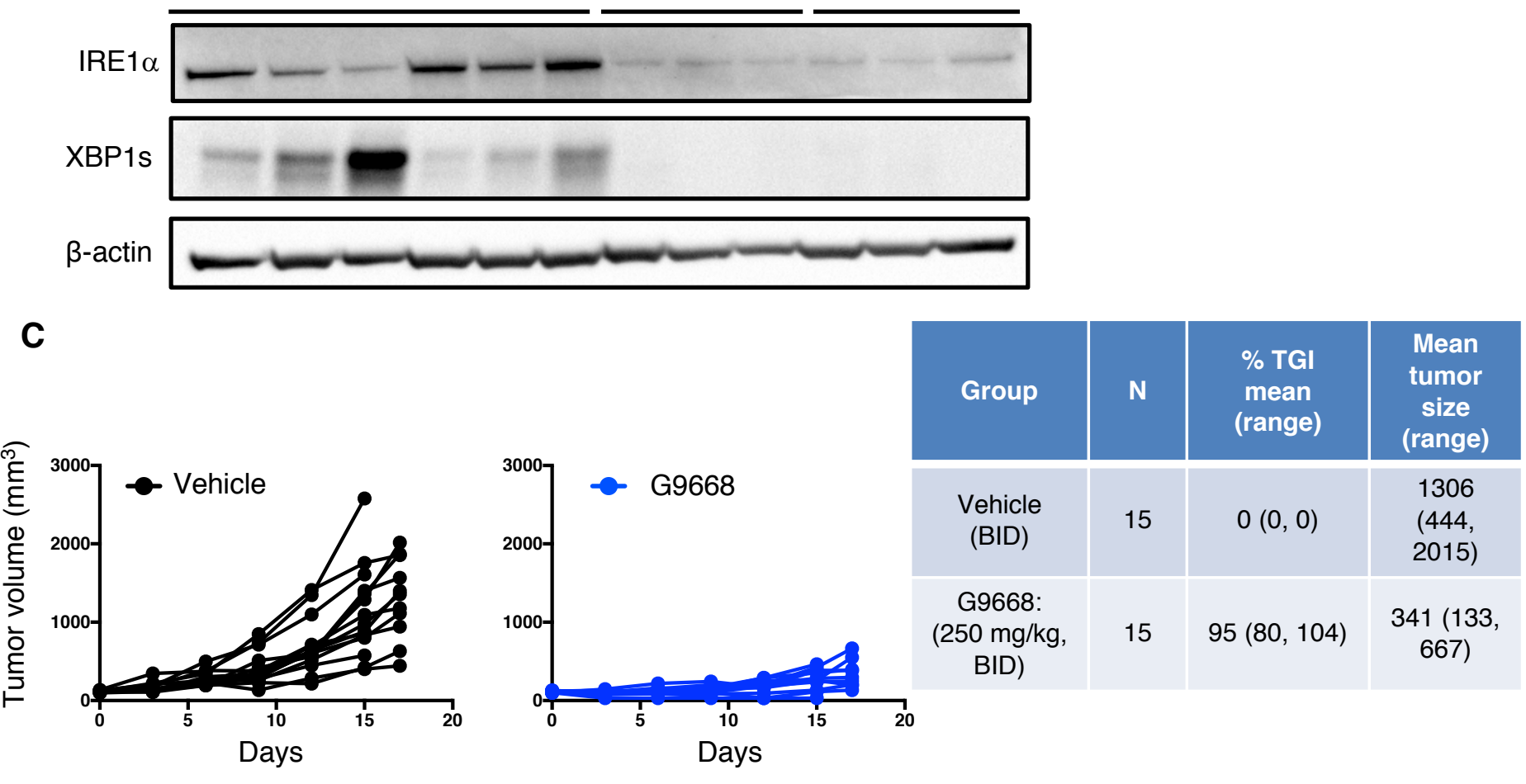

D

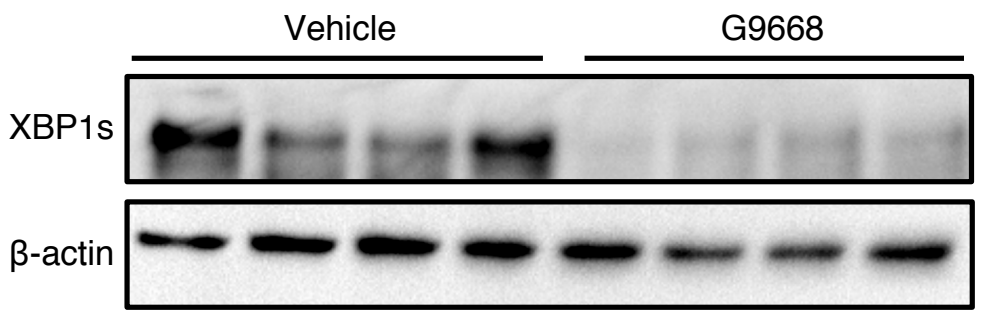

Figure S5. IRE1 $\alpha$ inhibition attenuates CT26 tumor growth. (A, B) Animals were inoculated s.C. with parental or IRE1 $\alpha$ KO CT26 cells and tumor growth was measured over 27 days. (A) Final day tumor measurements, Scatter plots represent mean \pm SD. (B) IB analysis of IRE1 $\alpha$ expression and activation. (C, D) Mice were inoculated s.c. with CT26 cells, grouped out 7 days afterwards and treated with vehicle or G9668 (250 mg/kg, BID). (C) Growth trajectories of CT26 tumors in individual vehicle- and G9668-treated animals over 17 days and IB analysis of total tumor lysates (D) are depicted. Number of animals included in each study is noted in corresponding tables. 


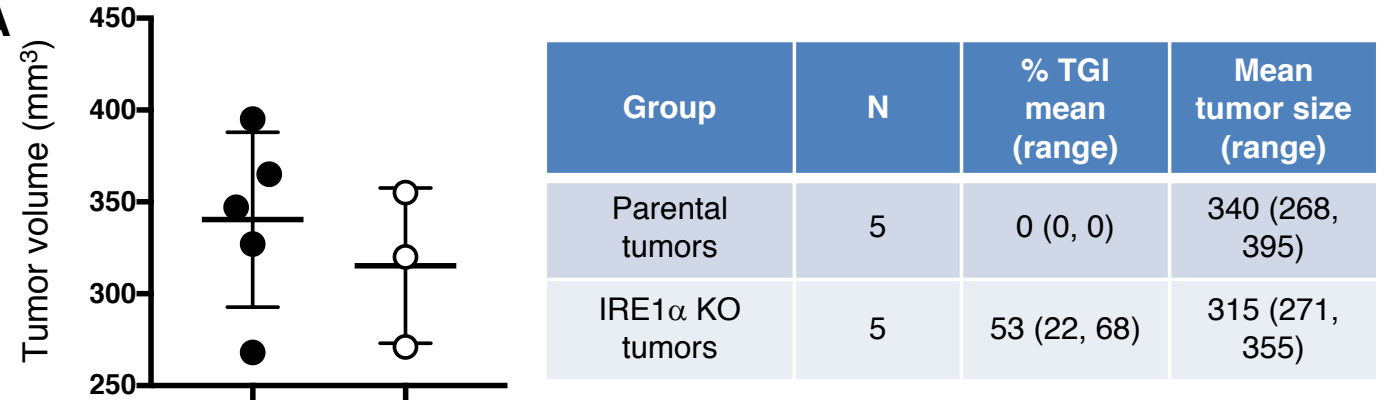

B

Parental IRE1 $\alpha \mathrm{KO}$

Parental

IRE $1 \alpha \mathrm{KO}$

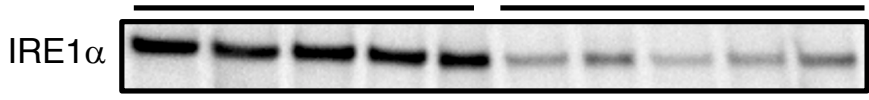

XBP1s

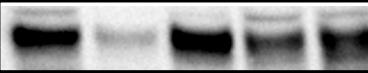

$\beta$-actin

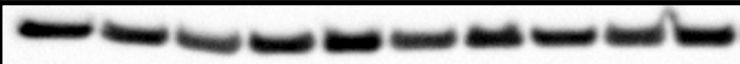

C
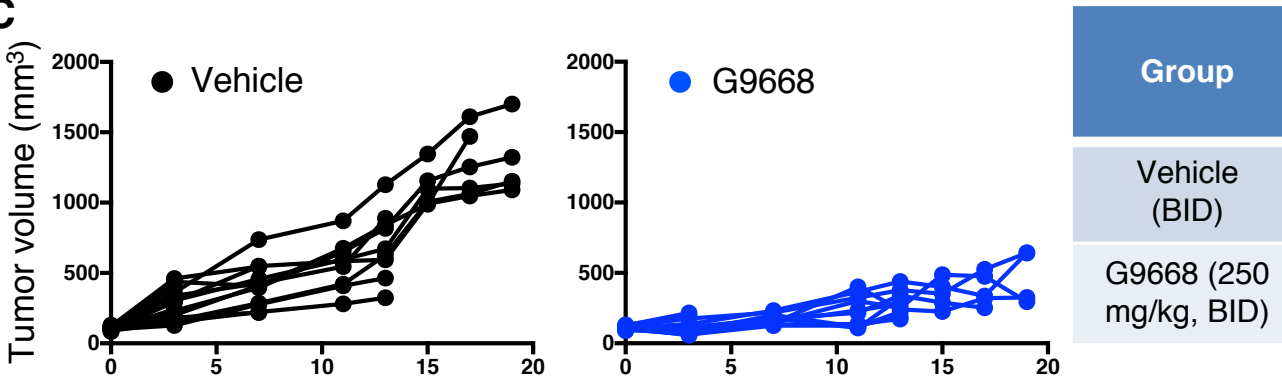

\begin{tabular}{|c|c|}
\hline $\mathbf{N}$ & $\begin{array}{c}\% \mathrm{TGI} \\
\text { mean } \\
\text { (range) }\end{array}$ \\
\hline 10 & $0(0,0)$ \\
\hline 10 & $\begin{array}{c}82(62 \\
91)\end{array}$ \\
\hline
\end{tabular}

Mean tumor

size (range)

Vehicle

G9668

D

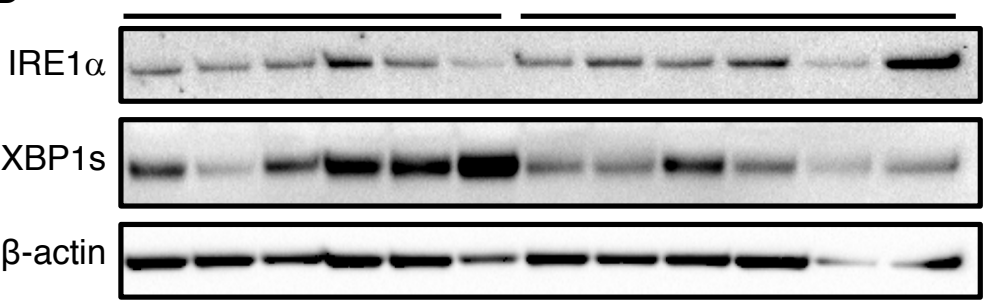

E

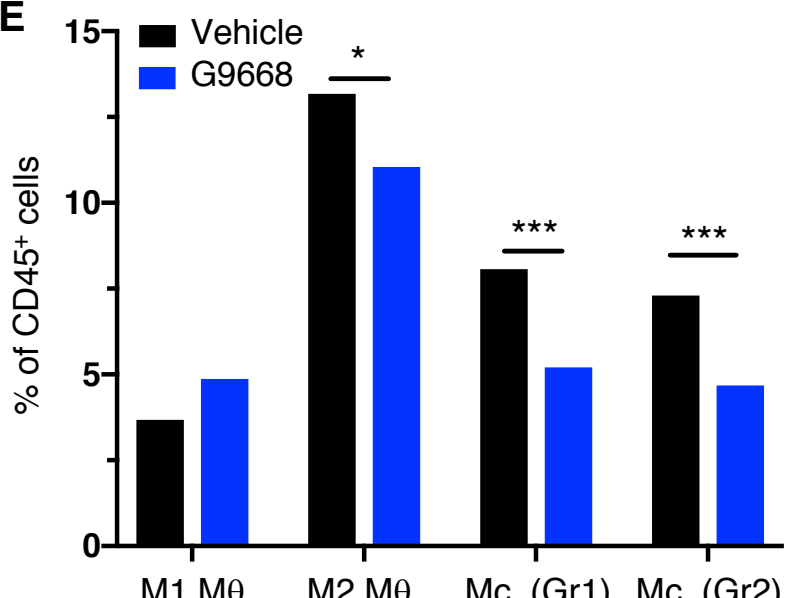

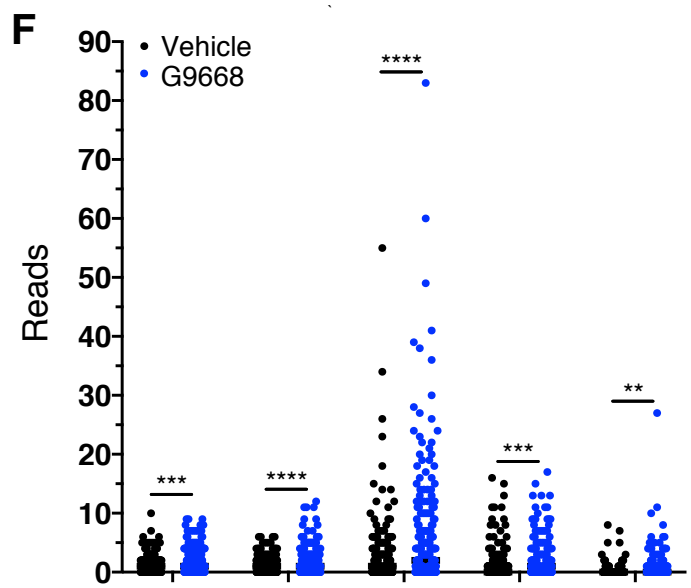

BLOS1 Fermt3 IRF7 RNF213SPON1

Figure S6. IRE1 $\alpha$ inhibition attenuates 4T1 tumor growth. (A-B) Animals were inoculated s.c. with parental or IRE1 $\alpha$ KO 4T1 cells and tumor growth was monitored over 25 days, with final measurements (A) and IB analysis of total tumor lysates (B) presented. (C-E) Mice were inoculated s.c. with 4 T1 cells, grouped out 7 days afterwards and treated with vehicle or G9668 (250 mg/kg, BID). (C) Tumor growth in individual animals was measured over 19 days, and (D) IRE1 $\alpha$ expression and activation were analyzed by IB. (E, F) Mice were treated with vehicle or G9668 for 6 days and tumors were then analyzed. (E) Transcript levels of indicated genes characterized as RIDD targets in tumor-infiltrating DCs. (F) Relative abundance of group 1 (Hcar) and group 2 (Hilpda) tumor-infiltrating monocytes (Mc.) and M1- or M2-polarized macrophages in vehicle- and G9668treated animals, analyzed by single-cell RNA sequencing data. ${ }^{*} P \leq 0.05$, ${ }^{* *} P \leq 0.01{ }^{* * *} P \leq 0.001$, ${ }^{* * *} P \leq 0.0001$. Number of animals included in each study is noted in corresponding tables. Scatter plots in panels $\mathbf{A}, \mathbf{E}$ and $\mathbf{F}$ represent mean $\pm \mathrm{SD}$. 


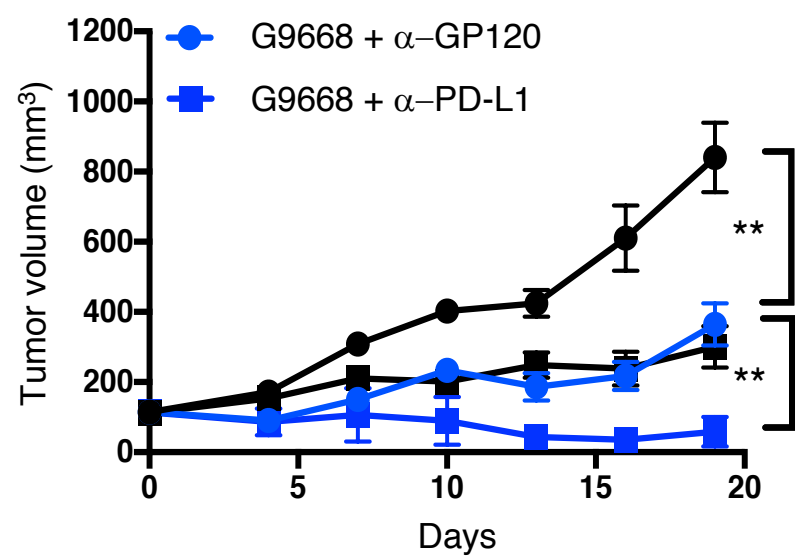

B
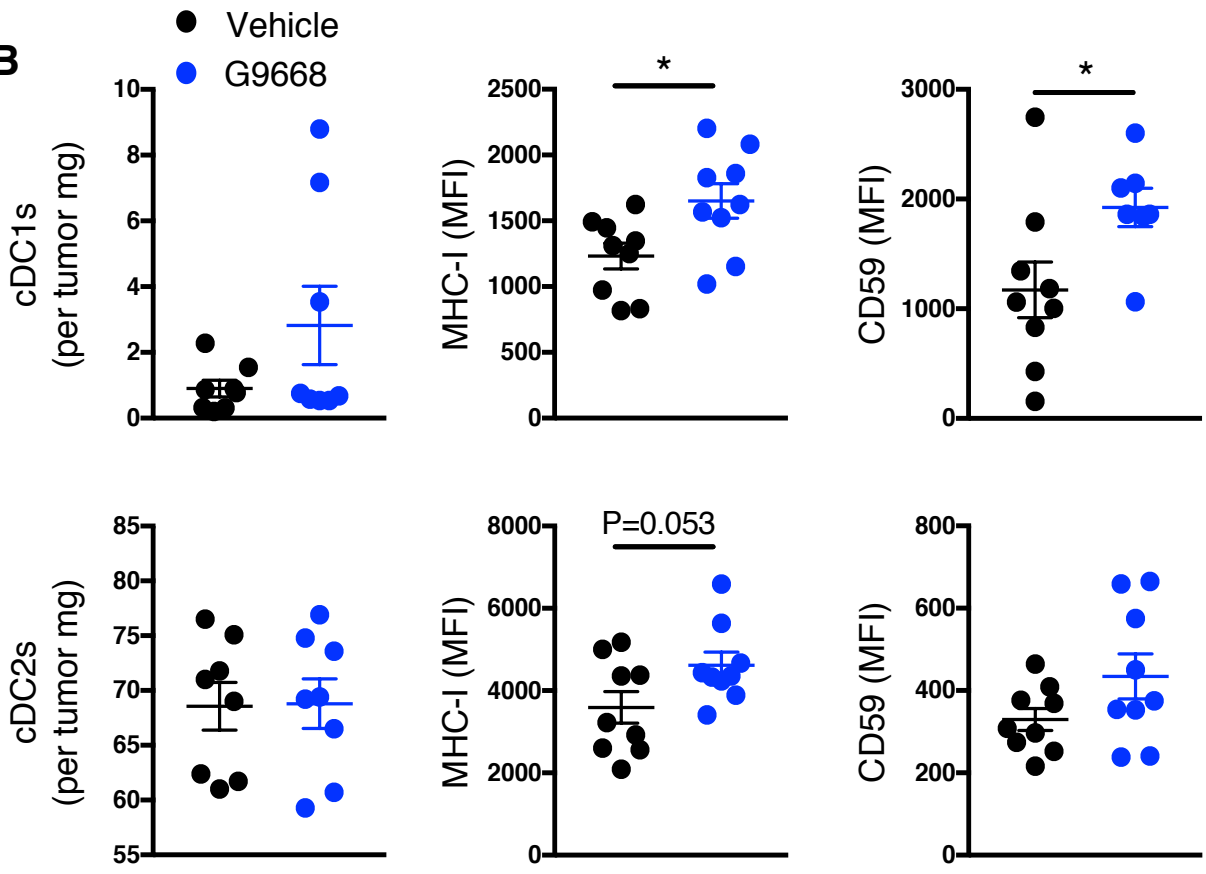

C
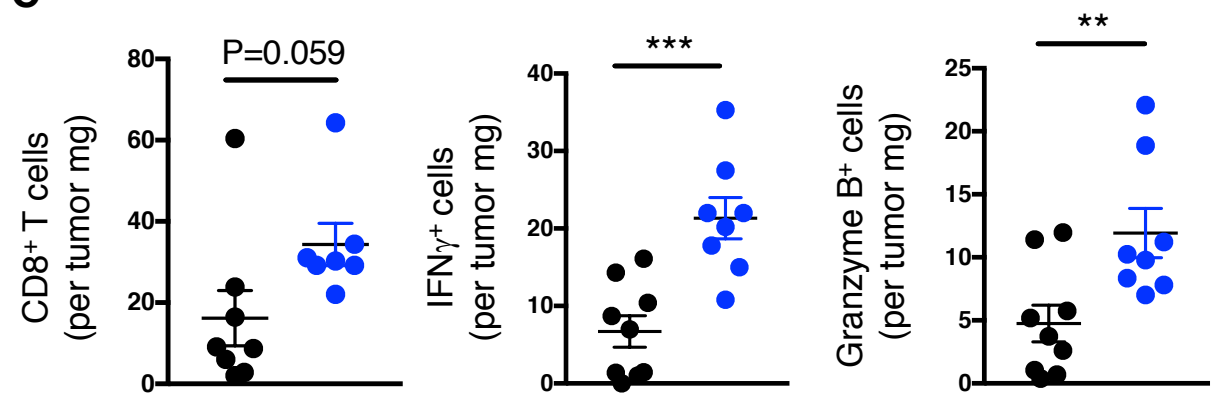

Figure 7. IRE1 $\alpha$ inhibition attenuates EMT6 tumor growth and synergizes with anti-PD-L1 antibody in conjunction with increased DC and CD8 $^{+}$T cell tumor infiltration and activation. Mice were inoculated orthotopically with EMT6 cells in the mammary fat pad, grouped out 7 days afterwards and treated with vehicle, G9668 (250 mg/kg, BID), anti-PD-L1 antibody (10 mg/kg at first dose, $5 \mathrm{mg} / \mathrm{kg}$ BIW thereafter), or the combination. (A) Tumor growth trajectories were measured over 19 days $(n=15)$. (B, C) Mice were treated with G9668 for 7 days and then sacrificed $(n=9)$. (B) Abundance of tumor $\mathrm{CDC} 1 \mathrm{~s}$ and $\mathrm{CDC} 2 \mathrm{~s}$, as well as expression of class I MHC and CD59, were measured by flow cytometry. Total DCs were characterized as F4/80 low, CD11 $\mathrm{c}^{+}$and class II MHChigh, while cDC1s were characterized as CD103+ XCR1+ CD11 - . (C) Abundance and activation marker expression of tumor-infiltrating CD8 ${ }^{+} \mathrm{T}$ cells were assayed by flow cytometry. Analysis was performed using oneway ANOVA for panel A and unpaired, two-tailed $t$ test for panels $\mathbf{B}$ and $\mathbf{C},{ }^{*} \mathrm{P} \leq 0.05,{ }^{* *} \mathrm{P} \leq 0.01,{ }^{* * *} \mathrm{P} \leq 0.001$. Scatter plots in all panels represent mean $\pm S D$. 
A

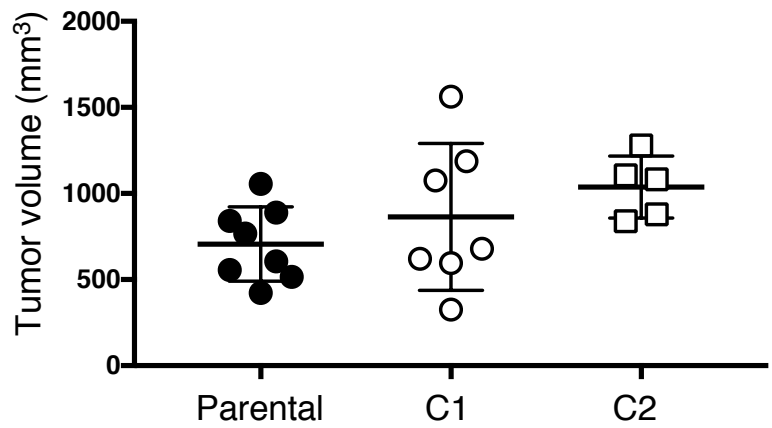

\begin{tabular}{|c|c|c|c|}
\hline Group & N & $\begin{array}{c}\% \text { TGI mean } \\
\text { (range) }\end{array}$ & $\begin{array}{c}\text { Mean } \\
\text { tumor size } \\
\text { (range) }\end{array}$ \\
\hline $\begin{array}{c}\text { Parental } \\
\text { tumors }\end{array}$ & 10 & $0(0,0)$ & $\begin{array}{c}706(422, \\
1055)\end{array}$ \\
\hline IRE1 $\alpha$ KO & 10 & $-13(-46,47)$ & $\begin{array}{c}864(326, \\
1563)\end{array}$ \\
\hline tumors $(\mathrm{C} 1)$ & & & $1037(839$, \\
\hline IRE1 $\alpha$ KO & 10 & $-8(-22,-1)$ & $1279)$ \\
\hline tumors $(\mathrm{C} 2)$ & & & \\
\hline
\end{tabular}

B

Parental

IRE1 $\alpha$ KO (C1)

IRE1 $\alpha$ KO (C2)

$\operatorname{IRE} 1 \alpha \longrightarrow-$

XBP1s

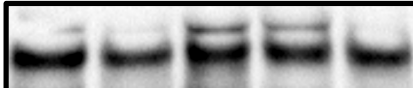

GAPDH

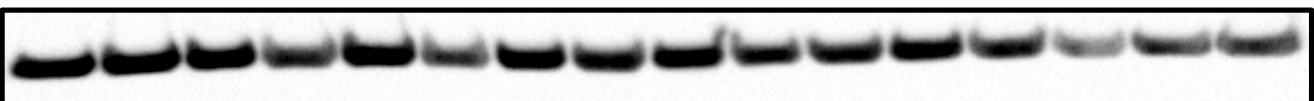

C

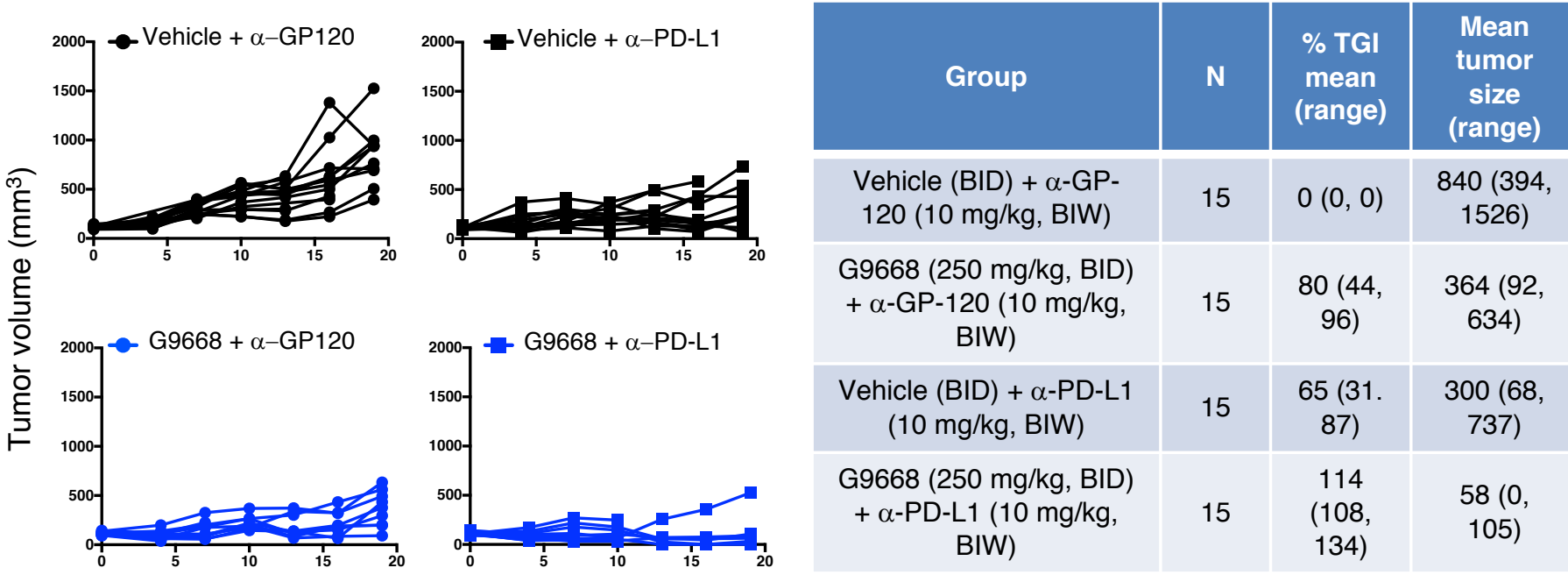

D

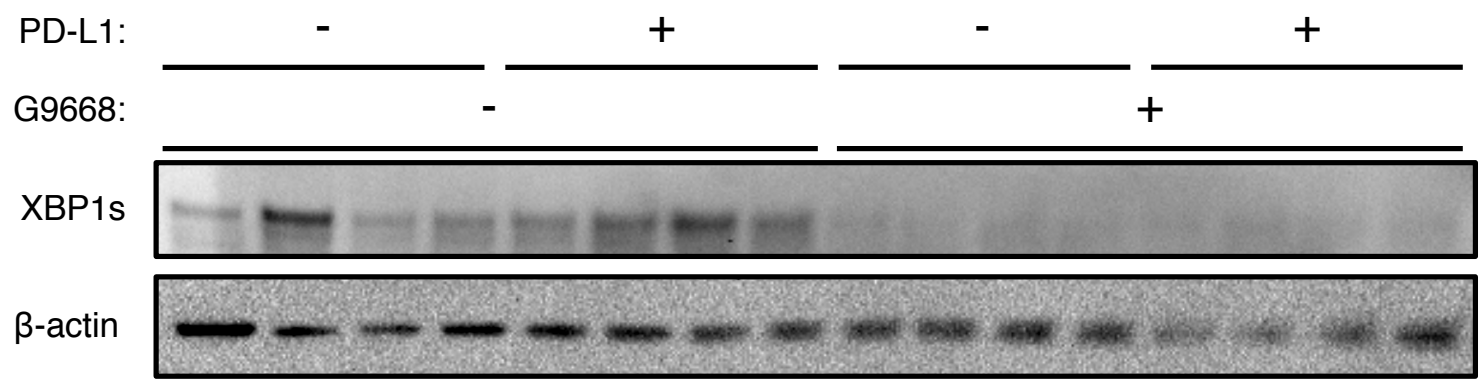

Figure S7. IRE1 $\alpha$ inhibition attenuates EMT6 tumor growth and synergizes with anti-PD-L1 antibody. (A, B) Mice were inoculated orthotopically with WT or IRE $1 \alpha$ KO EMT6 cells and tumor growth was measured over 24 days, with final tumor measurements (scatter plots represent mean \pm SD) (A) and IB analysis of total tumor lysates (B) presented. (C, D) Mice were inoculated with WT or IRE1 $\alpha$ KO EMT6 cells, grouped out 7 days afterwards and treated with vehicle, G9668 (250 mg/kg, BID), anti-PD-L1 antibody (10 mg/kg at first dose, $5 \mathrm{mg} / \mathrm{kg} \mathrm{BIW}$ thereafter), or the combination. (C) Tumor growth trajectories were measured over 19 days. (D) IRE1 $\alpha$ activation was analyzed by IB. Number of animals included in each study is noted in corresponding tables. 